\title{
In Vitro and In Vivo Metabolite Identification Studies for the New Synthetic Opioids Acetylfentanyl, Acrylfentanyl, Furanylfentanyl, and 4-Fluoro-Isobutyrylfentanyl
}

Shimpei Watanabe, Svante Vikingsson, Markus Roman, Henrik Green, Robert Kronstrand and Ariane Wohlfarth

The self-archived version of this journal article is available at Linköping University Institutional Repository (DiVA):

http:/ / urn.kb.se/ resolve?urn=urn:nbn:se:liu:diva- 139392

N.B.: When citing this work, cite the original publication.

Watanabe, S., Vikingsson, S., Roman, M., Green, H., Kronstrand, R., Wohlfarth, A., (2017), In Vitro and In Vivo Metabolite Identification Studies for the New Synthetic Opioids Acetylfentanyl, Acrylfentanyl, Furanylfentanyl, and 4-Fluoro-Isobutyrylfentanyl, AAPS J ournal, 19(4), 1102-1122. https:// doi.org/ 10.1208/ s12248-017-0070-z

Original publication available at:

https:// doi.org/ 10.1208/ s12248-017-0070-z

Copyright: American Association of Pharmaceutical Scientists http:// www.aapsj.org/ 


\section{In vitro and in vivo metabolite identification studies for the new synthetic opioids acetylfentanyl, acrylfentanyl, furanylfentanyl and 4-fluoro-isobutyrylfentanyl}

Shimpei Watanabe ${ }^{1}$, Svante Vikingsson ${ }^{2}$, Markus Roman ${ }^{3}$, Henrik Green ${ }^{2,3}$, Robert Kronstrand ${ }^{2,3}$ and Ariane Wohlfarth ${ }^{2,3}$

${ }^{1}$ Centre for Forensic Science, School of Mathematical and Physical Sciences, University of Technology Sydney (UTS), PO Box 123, Broadway, NSW 2007, Australia

${ }^{2}$ Division of Drug Research, Department of Medical Health Sciences, Linköping University, 58185 Linköping, Sweden

${ }^{3}$ Department of Forensic Genetics and Forensic Toxicology, National Board of Forensic Medicine, 58758 Linköping, Sweden

Corresponding author:

Dr. Ariane Wohlfarth

National Board of Forensic Medicine

Department of Forensic Genetics and Forensic Toxicology

58758 Linköping

Sweden

Phone: +46104834346

Fax: +46104834199

Email: ariane.wohlfarth@rmv.se

Running head: Metabolism of four new fentanyl analogs

Keywords: Human hepatocytes, Authentic human urine samples, LC-HRMS, Fentanyl analogs, Metabolite identification 


\begin{abstract}
New fentanyl analogs have recently emerged as new psychoactive substances and have caused numerous fatalities worldwide. To determine if the new analogs follow the same metabolic pathways elucidated for fentanyl and known fentanyl analogs, we performed in vitro and in vivo metabolite identification studies for acetylfentanyl, acrylfentanyl, 4-fluoroisobutyrylfentanyl and furanylfentanyl. All compounds were incubated at $10 \mu \mathrm{M}$ with pooled human hepatocytes for up to $5 \mathrm{~h}$. For each compound, four or five authentic human urine samples from autopsy cases with and without enzymatic hydrolysis were analyzed. Data acquisition was performed in data-dependent acquisition mode during liquid-chromatography high-resolution mass spectrometry analyses. Data was analyzed 1) manually based on predicted biotransformations and 2) with MetaSense software using data-driven search algorithms. Acetylfentanyl, acrylfentanyl and 4-fluoroisobutyrylfentanyl were predominantly metabolized by $\mathrm{N}$ dealkylation, cleaving off the phenethyl moiety, monohydroxylation at the ethyl linker and piperidine ring as well as hydroxylation/methoxylation at the phenyl ring. In contrast, furanylfentanyl's major metabolites were generated by amide hydrolysis and dihydrodiol formation while the nor-metabolite was minor or not detected in case samples at all. In general, in vitro results matched the in vivo findings well, showing identical biotransformations in each system. Phase II conjugation was observed, particularly for acetylfentanyl. Based on our results, we suggest the following specific and abundant metabolites as analytical targets in urine: a hydroxymethoxy and monohydroxylated metabolite for acetylfentanyl; a monohydroxy and dihydroxy metabolite for acrylfentanyl; two monohydroxy metabolites and a hydroxymethoxy metabolite for 4-fluoro-isobutyrylfentanyl and a dihydrodiol metabolite and the amide hydrolysis metabolite for furanylfentanyl.
\end{abstract}

Keywords: Human hepatocytes, Authentic human urine samples, LC-HRMS, Fentanyl analogs, Metabolite identification 


\section{Introduction}

Synthetic opioids are a class of new psychoactive substances (NPS) mostly consisting of analogs of the prescription drug fentanyl (Figure 1) Since 2012, they have caused an alarming number of fatalities worldwide [1]. Fentanyl itself is a potent $\mu$-opioid receptor agonist [2] and is estimated to be at least 50 times more potent than morphine [3]. Although therapeutically prescribed as an analgesic since the 1960s, fentanyl has also been abused for its euphoric effects with fatalities occurring due to respiratory depression followed by apnea $[4,5]$.

A plethora of fentanyl analogs have been developed over the last decades [6], some examples are shown in Figure 1. Approved medications are e.g. alfentanil, sufentanil and remifentanil for use in humans and carfentanil for use in animals. 'Older' fentanyl analogs abused recreationally are 3-methylfentanyl, $\alpha$-methylfentanyl and $\beta$-hydroxyfentanyl [7]. The analogs that recently appeared as NPS are usually generated by modification or replacement of fentanyl's propionyl chain (acetylfentanyl, acrylfentanyl, butyrylfentanyl, isobutyrylfentanyl, furanylfentanyl, ocfentanil) or replacement of the ethylphenyl moiety (isofentanyl, ß-hydroxythiofentanyl). Existing variants are further substituted with fluoro, chloro or methoxy substituents at the $\mathrm{N}$ phenyl ring $[8,9]$. Not only are the fentanyl analogs highly potent, their potencies are also variable, making it difficult for the users to dose the drugs correctly and increasing the risk of accidental overdoses.

To understand and monitor the abuse of fentanyl analogs reliable analytical methods are needed in clinical and forensic laboratories. Urine is still the matrix of choice for drug testing due to the non-invasive nature of sampling, well-established procedure and admissibility. Less than $8 \%$ of fentanyl is excreted unchanged. Approximately $85 \%$ is excreted within $72 \mathrm{~h}$ in feces and urine, the majority as metabolites [10] mainly as norfentanyl generated by $\mathrm{N}$-dealkylation at the piperidine nitrogen. Minor metabolites are despropionylfentanyl, which is formed by carboxamide hydrolysis, and hydroxyfentanyl and hydroxynorfentanyl metabolites, both hydroxylated at the propionyl moiety [11, 12].

To date, information about metabolism of fentanyl analogs, which have been found as drugs of abuse, is limited to a few studies: So far, metabolism of $\alpha$-methylfentanyl in rat urine [13], 3methylfentanyl in rat urine [14], isofentanyl in rat urine [14], butyrylfentanyl in human blood, tissues and urine [15] and acetylfentanyl in human liver microsomes and rat urine [16] and human urine [17] have been investigated. Some analogs, such as $\alpha$-methylfentanyl, 3methylfentanyl, isofentanyl and acetylfentanyl, were metabolized to the nor-metabolite, similar to fentanyl. Minor metabolites were produced by hydroxylation, dihydroxylation and carboxylation, often in combination with $N$-dealkylation. For acetylfentanyl, however, 
hydroxylation and hydroxylation/methoxylation at the phenethyl moiety dominated over $\mathrm{N}$ dealkylation. For butyrylfentanyl, hydroxylation and carboxylation dominated, while the norand desbutyryl metabolite were minor.

Based on the current state of knowledge, we hypothesize that suitable analytical targets in urine for new fentanyl analogs can often, but not always, be predicted based on fentanyl's metabolic pathway demonstrating the need to perform individual metabolism studies. Therefore, the aims of this study were to perform metabolism studies for four new fentanyl analogs, acetylfentanyl, acrylfentanyl, 4-fluoro-isobutyrylfentanyl and furanylfentanyl. We analyzed authentic human urine samples that were available from casework and also incubated the drugs with human hepatocytes. Sample analysis was performed under identical conditions with liquid chromatography high-resolution mass spectrometry (LC-HRMS) allowing for direct comparison between hepatocyte and urine samples and producing accurate mass measurements for metabolite molecules and fragment ions. Incubation with human hepatocytes provides in vitro metabolite profiles that are often similar to what is found in humans $[18,19]$. Individual incubation under controlled conditions eliminates analogs as potential source of metabolites. However, in vitro models are inherently limited running the risk of missing metabolites or misinterpreting their relevance. Conversely, authentic human urine samples contain the real human metabolites formed from the whole organism. They usually come, however, with limited information about the intake itself, e.g. time before sampling, identity and purity of the drug or co-consumption of other compounds. A combination of both systems, complementing advantages and compensating for disadvantages, seems to be the road forward. 


\section{Materials and Methods}

\section{Chemicals and reagents}

Acetylfentanyl, acrylfentanyl, furanylfentanyl and 4-fluoro-isobutyrylfentanyl were purchased as powders from Cayman Chemical (Ann Arbor, USA), diclofenac from Sigma (Stockholm, Sweden). Cryopreserved hepatocytes LiverPool (10-donor-pool), InVitro Gro HT and InVitro Gro KHB media were obtained from Bioreclamation IVT (Brussels, Belgium). Liquid chromatography mass spectrometry grade acetonitrile, water, methanol and formic acid were from Fisher Scientific (Gothenburg, Sweden), ammonium formate from Fluka (Sigma-Aldrich, Stockholm, Sweden), ammonium acetate and acetic acid from Merck (Darmstadt, Germany). The $\beta$ glucuronidase/sulfatase mixture (Helix pomatia) was purchased from Roche (Mannheim, Germany). Ultra-pure water was prepared in-house using a MilliQ Gradient 10 production unit (Millipore, Billerica, USA).

Incubation with human hepatocytes \& sample preparation

Cryopreserved human hepatocytes were thawed at $37^{\circ} \mathrm{C}$ and transferred into InVitro Gro HT medium. The solution was centrifuged at $100 \mathrm{~g}$ for $4 \mathrm{~min}$, the supernatant aspirated and the hepatocyte pellet suspended in Krebs-Henseleit buffer (KHB). After centrifugation at $60 \mathrm{~g}$ for 4 min and aspiration of the supernatant the pellet was re-suspended in KHB. Using Trypan Blue $(0.4 \% \mathrm{v} / \mathrm{v})$ dye exclusion method, cell viability was determined as $100 \%$. Drugs were incubated at $10 \mu \mathrm{mol} / \mathrm{L}$ with human hepatocytes $(125,000$ cells $/ 125 \mu \mathrm{L}$ total volume/well) in a 96 -well plate at $37^{\circ} \mathrm{C}$ for 1,3 and $5 \mathrm{~h}$. The reaction was quenched by $125 \mu \mathrm{L}$ ice-cold acetonitrile. Organic solvent content was $\leq 0.4 \%$. A positive control with diclofenac, a negative control without drugs and degradation controls without hepatocytes were included. After centrifugation the supernatant was stored at $-20^{\circ} \mathrm{C}$. Samples were injected undiluted onto the liquid chromatography-quadrupole time-of-flight mass spectrometer (LC-QTOF); injection volume was $1 \mu \mathrm{L}$.

\section{Authentic human urine specimens \& sample preparation}

Four or five human urine specimens for each fentanyl analog from fatal overdose cases were used for metabolite profiling. A corresponding blood sample had always confirmed positive for the respective parent compound in the routine TOF screening [20] without showing presence of other fentanyl analogs. For all cases, the cause of death was ruled to be an overdose with the 
respective fentanyl analog, except in four cases, which were ruled intoxication with the fentanyl analog in combination with oxycodone (4-fluoroisobutyrylfentanyl case sample \#2), alcohol (4fluoroisobutyrylfentanyl case sample \#4), pregabalin (Furanylfentanyl case sample \#1) or fentanyl (Furanylfentanyl case sample \#4). Each urine sample was analyzed with and without enzymatic hydrolysis: To cleave phase II conjugates, $100 \mu \mathrm{L}$ urine was incubated with $10 \mu \mathrm{L} \beta$ glucuronidase/sulfatase $(4.5 \mathrm{u} / \mathrm{mL}$ and $14 \mathrm{U} / \mathrm{mL}$, respectively) in $300 \mu \mathrm{L}$ ammonium acetate buffer ( $\mathrm{pH} \mathrm{5.0)}$ at $40^{\circ} \mathrm{C}$ for $2 \mathrm{~h}$. The non-hydrolyzed set of samples was diluted with $310 \mu \mathrm{L}$ ammonium acetate buffer only. One $\mu \mathrm{L}$ of each sample was injected onto the LC-QTOF system.

\section{LC-QTOF analysis}

Chromatographic separation was performed on an Agilent 1290 Infinity UHPLC system with an Acquity HSS T3 column (150 mm x $2.1 \mathrm{~mm}, 1.8 \mathrm{um}$ ) fitted with an Acquity VanGuard precolumn, both from Waters (Sollentuna, Sweden), at $60{ }^{\circ} \mathrm{C}$. Mobile phases were $10 \mathrm{mM}$ ammonium formate in $0.05 \%$ formic acid $(A)$ and $0.05 \%$ formic acid in acetonitrile $(B)$ and were run in gradient at a flow rate of $0.5 \mathrm{~mL} / \mathrm{min}$ starting at $1 \% \mathrm{~B}$ until $0.6 \mathrm{~min}$, ramped to $5 \% \mathrm{~B}$ at $0.7 \mathrm{~min}, 50 \% \mathrm{~B}$ at $13 \mathrm{~min}, 95 \% \mathrm{~B}$ at $15 \mathrm{~min}$ until $18 \mathrm{~min}$, then ramped down to $1 \% \mathrm{~B}$ at $18.1 \mathrm{~min}$ and re-equilibration until $19 \mathrm{~min}$.

Mass spectrometric data was obtained with an Agilent 6550 iFunnel QTOF mass spectrometer with a Dual Agilent Jet Stream electrospray ionization source. Auto MS/MS acquisition was performed in positive ion mode with the following conditions: scan range, $100-950 \mathrm{~m} / \mathrm{z}$ (MS) and $50-950 \mathrm{~m} / \mathrm{z}$ (MS/MS); precursor intensity threshold, 5000 counts; precursor number per cycle, 5; fragmentor voltage, $380 \mathrm{~V}$; collision energy, $3 \mathrm{eV}$ at $0 \mathrm{~m} / \mathrm{z}$ ramped up by $8 \mathrm{eV}$ per 100 $\mathrm{m} / \mathrm{z}$; gas temperature, $150{ }^{\circ} \mathrm{C}$; nebulizer gas pressure, $50 \mathrm{psig}$; sheath gas temperature, $375^{\circ} \mathrm{C}$. Automated calibration was in place during data acquisition.

\section{Manual and software-assisted data analysis}

Full scan MS and MSMS data sets were analyzed by Agilent MassHunter Qualitative Analysis (version B.07.00) using a PCDL library that contained known biotransformation of fentanyl and fentanyl analogs as well as reactions predicted by MetaSite ${ }^{\mathrm{TM}}$ ( $\mathrm{v} .5$, Molecular Discovery, Pinner, UK). Searching parameters were as follows: mass error 15 ppm, absolute peak area > 10,000 counts, maximum number of matches 5 , chromatogram extraction window 100 ppm.

Metabolites were evaluated based on the following criteria: mass error for protonated molecule being less than 5 ppm; consistent isotopic pattern; MSMS product ions consistent 
with proposed structure; retention time plausible for the proposed structure; appropriate peak shape; and absence of identical peaks in negative controls.

All in vitro and in vivo samples were also processed with MetaSense ${ }^{\mathrm{TM}}$ software (version 1.0, in combination with Spectrus Processor 2016.1.3 and DB Enterprise 2016.1.3, Advanced Chemistry Development, Inc., Toronto, ON, Canada). Processing options were as follows: MS accuracy $0.005 \mathrm{Da}$; three metabolite generations; minimum metabolite mass $150 \mathrm{Da}$; human specific and phase II metabolites included; minimum metabolite $>0.01 \%$ of the parent. 


\section{Results}

Hydroxydiclofenac was observed in the diclofenac positive control confirming hepatocyte metabolic activity. Any peaks that appeared either in the negative or degradation control were not considered as metabolites.

Metabolic profile of acetylfentanyl

In total, 32 acetylfentanyl metabolites ( $A 1$ to $A 32$, in increasing order of retention time, RT) were identified, all of them with mass errors $\leq 4.22 \mathrm{ppm}$. The parent drug was found in high abundance in all samples. Metabolites were formed via $\mathrm{N}$-dealkylation (A3) followed by hydroxylation ( $A 1, A 2)$, monohydroxylation ( $A 24, A 25, A 28, A 30)$ - preferably at the ethyl linker - followed by glucuronidation $(A 6, A 11, A 20)$ or sulfation $(A 17, A 23)$, dihydroxylation $(A 8, A 13$, $A 14, A 19)$ followed by glucuronidation $(A 5, A 10)$ or sulfation (A22), monohydroxylation and carbonylation ( $A 15, A 18)$, dihydrodiol formation (A4, $A 7)$, dihydroxylation with methylation at the phenyl ring (A26, $A 27, A 29)$ followed by glucuronidation (A9, $A 12)$ or sulfation $(A 21)$ as well as amide hydrolysis (A32) followed by hydroxylation (A16, $A 31)$. Retention times were between $2.77 \mathrm{~min}$ and $9.09 \mathrm{~min}$, with A32 eluting after the parent (RT $7.92 \mathrm{~min}$ ). The three sample sets showed different numbers of metabolites with different signal intensities: Specifically, in hepatocytes, seven metabolites were detected ( $33, A 4, A 6, A 18, A 24, A 26$ and A30). Based on MS peak areas in the $5 \mathrm{~h}$ sample, the nor-metabolite $A 3$ was most abundant followed by the monohydroxylated metabolite A24 and the dihydrodiol metabolite A4. In hydrolyzed urine, 24 metabolites were found showing a wider spectrum of first- and second-generation metabolites and including all hepatocyte metabolites. Ranking MS peak areas, the most dominant metabolite was the hydroxymethoxy metabolite A26, followed by $A 3$ and $A 24$. These findings are in general agreement with Melent'ev et al.'s study [17]. Finally, in non-hydrolyzed urine samples, many additional phase II metabolites were detected, out of 32 metabolites seven were glucuronides and four were sulfates. Generally, hydrolysis led to complete cleavage of the conjugates; exceptions occurred for A17 and A20. Table 1 lists all 32 metabolites with retention time, accurate mass of the protonated molecule, proposed metabolic transformation, elemental composition, mass error, diagnostic product ions and chromatographic peak areas in hepatocyte, hydrolyzed and non-hydrolyzed urine samples while Figure $\mathbf{2}$ shows the proposed metabolic pathway of acetylfentanyl and Supplementary Figure 1 the MS/MS spectra of selected metabolites and their proposed fragment pattern.

Metabolic profile of acrylfentanyl 
For acrylfentanyl, a total of 14 metabolites were identified with mass errors $\leq 4.48 \mathrm{ppm}$ (B1 to B14). The observed biotransformations were $N$-dealkylation (B1), monohydroxylation (B9, B10, B13) followed by glucuronidation (B3), dihydroxylation (B7, B8) followed by glucuronidation (B5), dihydrodiol formation (B2, B6), dihydroxylation with methylation (B11, B12) followed by glucuronidation (B4) or amide hydrolysis (B14). Acrylfentanyl was present in high abundance in all samples. Metabolite retention times were between 5.25 and $9.06 \mathrm{~min}$, the parent eluted at $8.85 \mathrm{~min}$. Preferred molecular site of hydroxylation was the ethylphenyl moiety. In hepatocytes, eight metabolites were observed (B1, B2, B6, B9, B10, B11, B13 and B14), of which the normetabolite $\mathrm{B} 1$ and the monohydroxylated metabolites $\mathrm{B} 13$ and $\mathrm{B} 9$ were the most abundant metabolites after $5 \mathrm{~h}$ incubation. In hydrolyzed urine samples, twelve metabolites were detected with B1 being the major metabolite followed by B9 and B8. In total, three glucuronides B3, B4 and B5 were identified, which could be successfully hydrolyzed by the enzyme mixture, notably increasing the peak areas of the corresponding aglycones B9, B11 and B8. Table 2 provides an overview on all acrylfentanyl metabolites, Figure 3 depicts the proposed metabolic pathway and Supplementary Figure $\mathbf{2}$ shows MSMS spectra of metabolites and their proposed fragmentation pattern.

\section{Metabolic profile of 4-fluoro-isobutyrylfentanyl}

For 4-fluoro-isobutyrylfentanyl, 17 metabolites were identified (C1 to C17) with mass errors $\leq$ 5.09 ppm. The metabolites were generated by $N$-dealkylation (C3), hydroxylation (C7, C8, C10, C11, C15, C17) followed by glucuronidation (C5), dihydroxylation (C9), dihydrodiol formation (C4), dihydroxylation with methylation $(\mathrm{C} 12, \mathrm{C} 13)$ followed by glucuronidation (C6), amide hydrolysis (C14), oxidative $\mathrm{N}$-dealkylation and further reduction of the keto group (C1), carboxylation (C2), and carbonylation (C16). Retention times were between 4.08 and $11.48 \mathrm{~min}$; the hydroxy metabolite $\mathrm{C} 17$ eluted after the parent (RT $10.38 \mathrm{~min}$ ). The parent drug was the most or second most abundant peak in hepatocyte and urine samples. In hepatocytes, nine metabolites were observed (C3, C8, C10, C12, C14-C17), of which the nor-metabolite C3 was the major metabolite in the $5 \mathrm{~h}$ sample, followed by the monohydroxylated metabolites $\mathrm{C} 15$ and C10. In hydrolyzed urine, eleven metabolites were detected (C1, C2, C3, C4, C7, C9-C13, C15) and although the subset was different from the one in hepatocytes, the major metabolites were almost identical with the only difference that hydroxymethoxy 4-fluoro-isobutyrylfentanyl (C12) was also abundant. In non-hydrolyzed urine, two additional glucuronides C5 and C6 were found. They were completely cleaved by hydrolysis, which was reflected in a significant peak area increase of C15 and C12, respectively. Table 3 provides an overview on all 4-fluoroisobutyrylfentanyl metabolites, Figure 4 depicts the proposed metabolic pathway and Supplementary Figure 3 shows MSMS spectra of metabolites and their proposed fragmentation patterns. 
Metabolic profile of furanylfentanyl

Finally, for furanylfentanyl, 14 metabolites (D1 to D14) were identified with mass errors $\leq 3.11$ ppm. With retention times between $3.56 \mathrm{~min}$ and $9.05 \mathrm{~min}$, all of them eluted before the parent (9.38 min). Metabolites were formed via $N$-dealkylation (D6), hydroxylation (D11, D13), amide hydrolysis (D14) followed by hydroxylation (D4, D8, D12) with glucuronidation (D3) or sulfation (D5), dihydrodiol formation (D10) followed by hydroxylation (D7) or N-dealkylation (D1), oxidative $N$-dealkylation and reduction of the keto group (D2), and furanyl ring opening and carboxylation (D9). In contrast to the other three fentanyls, amide hydrolysis and dihydrodiol formation led to the most abundant phase I metabolites in urine samples and although $\mathrm{N}$-dealkylation was the second most common reaction in hepatocytes, the normetabolite D6 was only minor in urine. Furanylfentanyl was abundant in hepatocytes over the whole incubation time, but showed less intense signals compared to the other fentanyl analog parents in the five urine samples. In hepatocytes, all metabolites but D3 were found. The amide hydrolysis metabolite D14 was the major metabolite, the nor-metabolite D6 and the dihydrodiol metabolite D10 ranked \#2 and \#3. In hydrolyzed urine samples, nine metabolites were detected (D1, D2, D4-D8, D10, D14) with D14 being the most abundant peak followed by D10, then D5. In non-hydrolyzed urine samples, one glucuronide (D3) and one sulfate (D5) were found as phase II metabolites. Enzymatic cleavage was successful for the glucuronide resulting in the appearance of D4, but failed for the sulfate. Table 4 provides an overview on all furanylfentanyl metabolites, Figure 5 depicts the proposed metabolic pathway and

Supplementary Figure 4 shows MSMS spectra of metabolites and their proposed fragmentation patterns. 


\section{Discussion}

\section{Structural elucidation of metabolites}

All four fentanyl analogs investigated in this study shared the phenethylpiperidine substructure. Upon collision-induced dissociation, several characteristic fragments can be derived from it, which were used to determine the type of biotransformation and where it could have occurred: If the phenethylpiperidine structure is unchanged, as is the case in all parent molecules and many metabolites, two major signals are usually found in the MSMS spectrum, one at $\mathrm{m} / \mathrm{z}$ 105.0699 , associated with the phenethyl moiety, and one at $m / z 188.1434$, corresponding to the complete structure. Depending on the compound's peak intensity and preferred fragmentation behavior, also minor fragments at $\mathrm{m} / \mathrm{z} 84.0808$ (unchanged piperidine ring) or 132.0808 (phenethyliminomethylium ion) can be detectable.

\section{Acetylfentanyl metabolites}

The MSMS spectrum of acetylfentanyl showed the three aforementioned peaks at $\mathrm{m} / \mathrm{z}$ 105.0697, 132.0801 and 188.1434. The most abundant metabolite A3 was the nor-metabolite, which is generated by $N$-dealkylation at the piperidine nitrogen resulting in a loss of the phenethyl moiety. The MSMS spectrum showed one intense fragment ion at $m / z 84.0805$, but lacked $\mathrm{m} / \mathrm{z} 105.0699$ and 188.1434. Minor fragment ions were observed at $\mathrm{m} / \mathrm{z} 94.0645$ (anilinyl moiety) and 136.0750 ( $N$-phenylacetamide moiety). Hydroxylation of A3 yielded A1 and $A 2$ with the major fragment ion at $m / z 84.0809$ and 84.0803 , respectively, suggesting the position of hydroxylation at the acetyl moiety or $N$-phenyl ring.

Monohydroxylated metabolites were identified by the addition of $15.9949 u(+0)$ to the mass of acetylfentanyl: The most abundant hydroxy metabolite A24 was hydroxylated at the ethyl linker as indicated by $m / z 121.0643$ (hydroxyphenethyl) and $m / z$ 103.0535, its water loss fragment ion. An aliphatic hydroxy group is likely, because water loss is uncommon at aromatic rings [21]. A25 and A28 were either hydroxylated at the $N$-phenyl ring or the acetyl moiety $(\mathrm{m} / \mathrm{z}$ $188.1428 / 188.1430)$. A30 is generated by hydroxylation at the piperidine ring, which is supported by the fragment ions at $\mathrm{m} / \mathrm{z}$ 105.0691, 204.1392 (hydroxyphenethylpiperidinyl) and the corresponding water loss peak at $m / z$ 186.1279.

The four dihydroxylated metabolites were identified by a mass shift of $31.9898 \mathrm{u}(+20)$ compared to the parent. The most dominant dihydroxylated metabolite was A14, which was hydroxylated once at the ethyl linker and once at the adjacent phenyl ring. The fragment ions at $\mathrm{m} / \mathrm{z} 220.1330$ and 137.0595 can be associated with dihydroxyphenethylpiperidine and 
dihydroxyphenethyl, respectively, while $m / z 119.0488$ represents the corresponding water loss ion from $\mathrm{m} / z$ 137.0595. A8 is suggested to be hydroxylated once on each phenyl ring; the presence of $\mathrm{m} / \mathrm{z} 121.0648$ and absence of $\mathrm{m} / \mathrm{z} 103.0542$ indicates aromatic hydroxylation and $\mathrm{m} / \mathrm{z} 84.0806$ and 204.0378 exclude the possibility of a second hydroxy group at the piperidine ring. A13's MSMS spectrum showed fragment ions at $\mathrm{m} / \mathrm{z} 107.0491$ (hydroxytoluene) and $\mathrm{m} / \mathrm{z}$ 202.1230 (water loss ion from $\mathrm{m} / \mathrm{z} 220.1332$ indicating two hydroxy groups at the phenethylpiperidine moiety). A19 is likely hydroxylated twice at the $N$-phenyl ring $(\mathrm{m} / \mathrm{z}$ 105.0694 and 188.1433) serving as the precursor for A27.

Interestingly, three metabolites generated by dihydroxylation and methylation of one of the hydroxy groups were also observed, one of them (A26) in high abundance: A26 and A29 showed similar characteristic fragment ions. The ions at $m / z 151.0758$ suggest presence of a hydroxy and a methoxy group at the phenethyl moiety. A loss of methanol will then generate the fragment ion at $m / z 119.0490$. The methylation reaction is probably catalyzed by catecholO-methyltransferase, an enzyme that is involved in the metabolism of catecholic neurotransmitters, such as adrenaline, noradrenaline and dopamine [22], and xenobiotics like MDMA, MDEA and MBDB [23]. The literature shows that the hydroxy group in meta position is preferred for methylation, suggesting that A26 is methylated there. In contrast, A27 was dihydroxylated and methylated at the $N$-phenyl ring as the phenethyl and piperidinyl moiety remained intact $(\mathrm{m} / \mathrm{z}$ 188.1426).

Two dihydrodiol metabolites (A4 and A7) are formed via the epoxide-diol-pathway, which has been described for other phenyl-ring-containing drugs as well, such as ethotoin, phenytoin, oxazepam and rofecoxib [24], as well as benzene [25]. A4, the intense isomer, is modified at the ethylphenyl ring. The fragment ion at $\mathrm{m} / \mathrm{z} 222.1489$ corresponds to the ethylphenylpiperidine substructure with dihydrodiol; $m / z 188.1070$ ( $\neq m / z$ 188.1434) indicates that the $N$-phenyl ring remained unchanged. As a water loss from one of the dihydrodiol hydroxy groups leads to rearomatization, we suggest that this reaction is extremely favorable explaining presence of $\mathrm{m} / \mathrm{z}$ 121.1559 , but absence of expected $\mathrm{m} / \mathrm{z}$ 139.0754. A similar phenomenon was observed for a dihydrodiol metabolite of AM2201 [26]. Notably, the dihydrodiol can be further metabolized by dihydrodiol dehydrogenase yielding a catechol - this reaction could produce the intermediate catechol of the two hydroxy methoxy metabolites A26 and A29. A7, only a minor metabolite, is modified at the $N$-phenyl ring $(\mathrm{m} / z 105.0699,188.1434)$ and is probably the precursor of $A 27$.

Carbonylation, probably at the ethyl linker ( $m / z$ 202.1221/202.1215), and hydroxylation, probably at the phenyl or piperidine ring $(\mathrm{m} / z$ 164.0707164.0704 and $218.1134 / 218.1199)$ produced two almost equally intense metabolites $A 15$ and $A 18$. The fragment ions at $\mathrm{m} / \mathrm{z}$ $118.0647 / 118.0651$ and $\mathrm{m} / \mathrm{z} 132.0806$ indicate an unchanged $N$-phenyl ring. 
A32 is formed by hydrolysis of the amide functional group cleaving off the acetyl moiety and leaving phenethylpiperidine unchanged ( $\mathrm{m} / \mathrm{z}$ 188.1423). Further hydroxylation leads to A16 hydroxylated at $N$-phenyl $(\mathrm{m} / \mathrm{z} 188.1416)$ and $A 31$ hydroxylated at the ethyl linker $(\mathrm{m} / \mathrm{z}$ 121.0637, 103.0545).

In the non-hydrolyzed samples, several glucuronides ( $A 5, A 6, A 9, A 10, A 11, A 12, A 20)$ and sulfates (A17, A21, A22, A23) were detected. Phase II metabolites were assigned to their respective phase I metabolites based on shared fragment ions, consistent elution behavior, matching relative intensities and increasing peak areas of the phase I metabolite after hydrolysis. Figure 2 shows the proposed individual assignments. Surprisingly, two glucuronides (A6 and A11) and two sulfates (A17 and A23), all clearly baseline-separated, were identified as possible conjugates of the abundant monohydroxylated metabolite A24. A possible explanation to explain the occurrence of two distinct glucuronide signals for one phase I metabolite is the formation of diastereomers. If the phase I metabolite has a stereogenic center (A24 does), the conjugation with another chiral molecule such as glucuronic acid will lead to diastereomers, which can be separated on non-chiral LC columns [27]. However, this hypothesis does not stand up to the fact that there are also two sulfates formed from A24. Possibly, the broad and intense A24 peak consists of two co-eluting isomers, both hydroxylated at the ethyl linker, but at different positions. The same phenomenon was observed for the dihydroxylated metabolite A14, to which two glucuronides ( $A 5$ and A10) could be assigned.

\section{Acrylfentanyl metabolites}

As expected, acryfentanyl fragmented to the two major product ions at $\mathrm{m} / \mathrm{z} 105.0697$ and 188.1441. Similarly to acetylfentanyl, acrylfentanyl underwent $N$-dealkylation at the piperidine nitrogen producing the major nor-metabolite B1 $(\mathrm{m} / z 84.0804$ without $\mathrm{m} / \mathrm{z} 105.0699$ and 188.1434). Monohydroxylated metabolites were either hydroxylated at the ethyl linker in B9 ( $\mathrm{m} / \mathrm{z}$ 121.0646, 103.0541), the $N$-phenyl ring or acryl moiety in $\mathrm{B} 10$ ( $\mathrm{m} / \mathrm{z} 105.0696,188.1370)$, or the piperidine ring in $\mathrm{B} 13(\mathrm{~m} / \mathrm{z} 105.0688,186.1261)$. One of the two dihydroxy metabolites, B7, was dihydroxylated at the $N$-phenyl ring or the acryl moiety $(\mathrm{m} / \mathrm{z} 105.0695,188.1441)$ while the other one, B8, was hydroxylated once each at the ethyl liker and the adjacent phenyl group as indicated by $m / z 137.0597$ and its water loss fragment at $m / z 119.0485$. In analogy to acetylfentanyl, we detected two dihydrodiol metabolites (B2, B6); one carrying the two hydroxy groups at the ethylphenyl ring $(\mathrm{m} / \mathrm{z} 121.0648)$ and the other one on the $N$-phenyl ring $(\mathrm{m} / z$ 105.0696, $\mathrm{m} / \mathrm{z}$ 188.1428). Both dihydroxylated/methylated metabolites B11 and B12 carried the hydroxy and methoxy group at the phenyl ring of the phenethyl moiety $(\mathrm{m} / z 151.0755$ and 151.0736; $\mathrm{m} / \mathrm{z} 119.0493$ and 119.0879 , the methanol loss fragment ions) and probably originate from B2. In view of strikingly different intensities for both isomers, we suggest that 
B11 is methylated at the preferred meta position and B12 at the less favored para position. Finally, the desacrylated metabolite B14, which is generated by amide hydrolysis, is characterized by the intact phenethylpiperidine moiety $(\mathrm{m} / \mathrm{z} 105.0687,188.1433)$ and is, in fact, identical to A32. The three glucuronides that were identified in non-hydrolyzed urine samples were assigned to the following aglycones based on shared fragment ions: B3 is the glucuronide of monohydroxy metabolite B9, B4 the glucuronide of the abundant dihydroxylated/methylated metabolite B11 and B5 the glucuronide of the most intense dihydroxylated metabolite B8.

\section{4-Fluoro-isobutyrylfentanyl metabolites}

The MSMS spectrum of 4-fluoro-isobutyrylfentanyl also showed the major fragment ions at $\mathrm{m} / \mathrm{z}$ 105.0698 and 188.1434 . The nor-metabolite C3 was characterized by one single intense product ion at $\mathrm{m} / \mathrm{z}$ 84.0806. Six monohydroxy metabolites were detected: $\mathrm{C} 7$ and $\mathrm{C} 8 \mathrm{had}$ an unchanged phenethylpiperidine moiety $(\mathrm{m} / \mathrm{z} 105.0693$ and 105.0698, 188.1407 and 188.1434, respectively); their relatively early retention time suggests aliphatic hydroxylation at the isobutyryl chain rather than aromatic hydroxylation. The abundant metabolite C10 was hydroxylated at the ethyl linker $(\mathrm{m} / \mathrm{z} 103.0543,121.0645)$. C11, in contrast, showed an ion at $\mathrm{m} / \mathrm{z} 121.0642$, but lacked the water loss fragment at $\mathrm{m} / \mathrm{z} 103.0542$ and hence can be hydroxylated at either the ethyl linker or the adjacent phenyl group. C15, one of the major metabolites, is hydroxylated at the piperidine ring $(\mathrm{m} / \mathrm{z} 105.0701,204.1365)$. C17 showed product ions at $m / z 105.0700$ and 164.0869 indicating that phenethyl moiety and $N$-phenyl ring are unchanged and leaving the site of modification to the piperidine ring. Interestingly, C17 eluted after the parent drug, which is rather uncommon for the supposedly more polar hydroxy metabolites. This phenomenon has been frequently observed for $\mathrm{N}$-oxides; thus, $\mathrm{C} 17$ is probably an $\mathrm{N}$-oxide [28-30]. The dihydroxylated metabolite $\mathrm{C} 9$ was hydroxylated once each at the ethyl linker and at the adjacent phenyl ring ( $\mathrm{m} / \mathrm{z} 119.0482,137.0590)$. Only one dihydrodiol metabolite (C4) was identified, which carried the dihydrodiol substructure at the ethylphenyl ring $(\mathrm{m} / \mathrm{z} 121.0639,234.1250)$ and likely is the precursor for C12 and C13. Interestingly, the fluoro substituent seems to have blocked dihydrodiol formation at the $N$-phenyl ring. The dihydroxylated/methylated metabolites $\mathrm{C} 12$ and C13, similar to acetyl- and acrylfentanyl, were modified at the phenyl ring $(\mathrm{m} / z 119.0493$ and $119.0473,151.0751$ and 151.0744, respectively), with the more abundant isomer $\mathrm{C} 12$ proposed to be methylated at meta position. Amide hydrolysis generated C14 with phenethylpiperidine moiety intact $(m / z 105.0699,188.1431)$ and the isobutyryl chain lost. We also observed oxidative $N$-dealkylation with further reduction of the formed keto group, which generated C1. The whole $N$-fluorophenylisobutamide moiety is cleaved off during this process, the phenethyl moiety remains intact ( $\mathrm{m} / \mathrm{z}$ 105.0698). Carboxylation to generate $\mathrm{C} 2$ occurred at the isobutyryl chain, the only plausible site $(\mathrm{m} / \mathrm{z}$ 
105.0689, 188.1443). C16's MSMS spectrum displayed a fragment ion at $m / z 202.1201$ indicating a carbonylated phenethylpiperidine moiety. The carbonyl group is proposed to be next to the piperidine nitrogen, as this would facilitate the formation of $m / z 148.0751$. Further evidence derives from the absence of $\mathrm{m} / \mathrm{z}$ 119.0491, which would be expected, if the carbonyl group were on the phenethyl moiety. In the non-hydrolyzed samples, the glucuronides $\mathrm{C} 5$ and C6, phase II conjugates of C15 and C12, were detected.

\section{Furanylfentanyl metabolites}

While acetyl-, acryl- and 4-fluoro-isobutyrylfentanyl differ only slightly in respect to the substituent at the amide group, furanylfentanyl contains a substantially different structure. Furan is an aromatic, heterocyclic system known to undergo characteristic bioactivation reactions, such as epoxidation and ring scission [31, 32], and the dominance of these reactions significantly affected furanylfentanyl's metabolic profile. Besides, the different structure seemed to favor an otherwise less important reaction, the amide hydrolysis.

Identical to the other analogs, furanylfentanyl generated the common two major fragment ions $\mathrm{m} / \mathrm{z} 105.0699$ and 188.1425. Amide hydrolysis produced the most abundant metabolite, D14, which showed an intact phenethylpiperidine moiety $(\mathrm{m} / \mathrm{z} 105.0697,188.1433)$ and could be further metabolized by hydroxylation either at the $N$-phenyl to yield D4 ( $\mathrm{m} / z$ 105.0698, $188.1435)$, at the ethyl linker to form $D 8(m / z 103.0529,121.0646)$ or at the piperidine ring to generate D12 ( $\mathrm{m} / \mathrm{z}$ 105.0690, 186.1269). The second most dominant biotransformation was epoxidation of furan followed by hydration, which yielded the dihydrodiol metabolite D10 $(\mathrm{m} / \mathrm{z}$ $105.0698,188.1440)$. Although the MSMS spectrum does not exclude the possibility of dihydrodiol formation at the $\mathrm{N}$-phenyl ring, we suggest that the furan ring is the more probable target [31]. Notably, furan epoxidation or ring opening to an $\alpha, ß$-unsaturated carbonyl intermediate can lead to reactive metabolites as shown for other furan-containing compounds like aflatoxin B1, ipomeanol and furosemide, which are known to cause hepatic and renal necrosis [31]. D10 was further hydroxylated at the piperidine ring to form D7 ( $\mathrm{m} / \mathrm{z} 103.0562$, 121.0649) or $N$-dealkylated to form the nor-metabolite D1 ( $\mathrm{m} / \mathrm{z}$ 84.0789). The nor-metabolite D6, abundant in hepatocytes but minor in human urine, showed the typical fragment ion at $\mathrm{m} / \mathrm{z}$ 84.0810 and also fragment ions at $\mathrm{m} / \mathrm{z} 188.0694$ (resulting from the loss of piperidine) and $\mathrm{m} / \mathrm{z}$ 95.0128 (further loss of phenylamine). D2 was formed by oxidative $N$-dealkylation and reduction of the keto group retaining the intact phenethyl moiety $(\mathrm{m} / \mathrm{z} 105.0698,188.1434)$. D11 and D13 were hydroxylated at the ethyl linker $(\mathrm{m} / z$ 103.0533, 121.0649) and the piperidine ring $(m / z$ 105.0685, 186.1274), respectively. Furanyl ring opening and subsequent carboxylation is proposed to generate D9 with $(\mathrm{m} / \mathrm{z} 105.0693,188.1448)$. In non-hydrolyzed samples, we identified D3 and D5, glucuronide (D3) and sulfate conjugate of D4. 
How well did hepatocyte study results correlate with the findings in human urine samples?

In general, major hepatocyte metabolites were in good agreement with major urine metabolites adding to the finding of previous studies that human metabolism can be wellpredicted by in vitro hepatocyte experiments [18, 27, 33]. The same biotransformations were observed and for each drug two out of the three major urine metabolites also ranked among the top three metabolites in hepatocytes (three out of four for 4-fluoro-isobutyrylfentanyl). Many deviations between hepatocytes and urine metabolites can be explained by the different time allowed for metabolism, which leads to fewer metabolites in general and a lower prevalence of $2^{\text {nd }}$ or $3^{\text {rd }}$ generation metabolites in hepatocytes. Another possible reason is the enrichment of polar and conjugated metabolites in urine. Different genotypes and phenotypes of the drug-metabolizing enzymes could be another factor for different metabolic profiles. However, such variance was expected to be reduced, at least partially, in the hepatocytes incubation since a pool from 10 donors was used in this study. For acetylfentanyl, the three most abundant urinary metabolites (\#1 hydroxymethoxy metabolite A26, \#2 hydroxy metabolite A24, \#3 nor-metabolite A3) were also generated by hepatocytes and ranked \#4, \#2, \#1 in terms of abundance in the 5h sample. Similarly, for acrylfentanyl, three out of the four most abundant urinary metabolites (\#1 nor-metabolite B1, \#2 hydroxy metabolite B9, \#3 dihydroxy metabolite B8 and \#4 hydroxymethoxy metabolite B11) were also observed in hepatocytes ranking \#1, \#3 and \#8. B8 was not detected, probably due to the relatively short incubation time. For the same reason, i.e. increased prevalence of $2^{\text {nd }}$ and $3^{\text {rd }}$ generation metabolites in urine, the second most abundant metabolite in hepatocytes B13 only ranked \#7 in the case samples. For 4-fluoro-isobutyrylfentanyl, the three most abundant metabolites (\#1 nor-metabolite C3, \#2 monohydroxy metabolites C10 and C15) were identical for hepatocytes and urine samples. The hydroxymethoxy metabolite $\mathrm{C} 12$, \#3 in urine samples, ranked \#8 in hepatocytes. For furanylfentanyl, the two major urinary metabolites (\#1 hydrolyzed metabolite D14, \#2 dihydrodiol metabolite D10) were detected after hepatocyte incubation ranking \#1 and \#3. However, the third most abundant metabolite in urine, D7, only ranked \#10 and would have never been predicted as an abundant in vivo metabolite. In fact, the hepatocyte experiment also suggested high prevalence for the nor-metabolite D6 (\#2 in hepatocytes), which strikingly mismatched the actual findings in the urine samples, illustrating the need to analyze in vivo human samples. Most likely, the nor-metabolite was further metabolized in vivo: We checked the data for $2^{\text {nd }}$ generation nor-metabolites and found intense signals for a potential nordesfuranyl metabolite at 0.92 min, albeit without MSMS spectral information. Steuer et al. observed a similar phenomenon with butyrylfentanyl, where the nor-metabolite was major in human liver microsome incubations but insignificant in a postmortem human urine and blood sample [34]. 
It should be noted that phase II conjugation can affect the availability of the phase I metabolite biomarkers. Particularly in acetylfentanyl urine samples, a several-fold increase (up to 50x) in phase I metabolite peak area was not uncommon after hydrolysis. Ten out of 32 metabolites were conjugates. While major metabolites, e.g. A24, A26 and A14, could be both glucuronidated and sulfated, less abundant metabolites, e.g. A29 and A30, were only glucuronidated. Phase II conjugation seemed to play a smaller role in acrylfentanyl, 4-fluoroisobutyrylfentanyl and furanylfentanyl metabolism, as we identified only 3, 2 and 2 phase II metabolites, respectively. Nevertheless, a hydrolysis step should always be included in the sample preparation.

\section{Which metabolites are suitable analytical targets for urine analysis?}

The studied fentanyl analogs were generally highly abundant in urine indicating that parent drugs are one of the most suitable targets nonetheless. However, all urine samples were from fatal overdose cases; consequently, parent drugs might be less abundant in non-overdose samples. As the window of detection of metabolites is usually longer than for the parent drugs and as the additional presence of metabolites increases the plausibility of the results, it is useful to target not only one, but two or three compounds including metabolites.

Target metabolites should generally be abundant, specific of the parent drug, and prevalent in most, if not all, case samples. As routine analysis usually involves a hydrolysis step and as reference standards usually become available earlier, phase I metabolites are preferred. It can be useful to target not only one, but two or three metabolites in addition to the parent drug. With this in mind, the nor-metabolite, although commonly abundant and prevalent, is a less suitable target because it has lost substantial parts of the molecule and consequently can be formed from similar drugs. The same is true for metabolites generated by oxidative $\mathrm{N}$ dealkylation and amide hydrolysis. Both are reactions that cleave off the specific moiety to distinguish between different analogs. As a result of that, in our study metabolites were shared across the different metabolic profiles and none of them represents a suitable analytical target: hydrolyzed metabolites (A32 = B14 = D14, RT $9.07 \mathrm{~min}$ ), hydrolyzed/hydroxylated metabolites ( $A 16=\mathrm{D} 4, \mathrm{RT} 5.70 \mathrm{~min}$ as well as $\mathrm{A} 31=\mathrm{D} 8, \mathrm{RT} 7.22 \mathrm{~min}$ ) and the metabolites generated by oxidative $\mathrm{N}$-dealkylation and reduction (C1 = D2, RT $4.06 \mathrm{~min})$.

Based on the aforementioned criteria, we suggest the following analytical targets: the hydroxymethoxy metabolite A26 and the monohydroxylated metabolite A24 for acetylfentanyl; the monohydroxy metabolite B9 and the dihydroxy metabolite B8 for acrylfentanyl and the monohydroxy metabolites C15 and C10 and the hydroxymethoxy metabolite C12 for 4-fluoroisobutyrylfentanyl. Regarding furanylfentanyl, none of the metabolites satisfied all criteria. The 
dihydrodiol metabolite D10 was not prevalent in all tested samples, but due to its abundance and specificity it should be considered the best target. In the absence of D10, e.g. in urine sample \#1 and \#3, the amide hydrolysis metabolite D14 may be targeted, although it does not prove furanylfentanyl consumption beyond doubt. As mentioned above, the abundance of major metabolites can be affected by different phenotypes of the metabolizing enzymes due to different genotypes, but also co-administered drugs (34).

\section{Is the metabolism of the new fentanyl analogs consistent with previous findings?}

In general, metabolism of fentanyl analogs follows similar pathways. Three of our four analogs, acetylfentanyl, acrylfentanyl and 4-fluoro-isobutyrylfentanyl, produced large amounts of the nor-metabolite, a hydroxyethyl metabolite and a hydroxymethoxy metabolite. This is consistent with previous findings that the nor-metabolite is a major metabolite of fentanyl [11] and other fentanyl analogs $[13,14]$ and that hydroxy metabolites are commonly observed for fentanyl and analogs $[11,13,14,34]$. Notably, the hydroxymethoxy metabolite has not been reported for fentanyl itself, but was observed for other analogs, e.g. 3-methylfentanyl, isofentanyl [14] and butyrylfentanyl [34]. The discrepancy might indicate that this metabolite was not searched for fentanyl in the previous studies.

In contrast, furanylfentanyl's major metabolites were generated by amide hydrolysis with/without hydroxylation and dihydrodiol formation while the nor-metabolite was not even detected in most of the urine samples. The aromatic furan ring, which has different reactivity from the side chains in the other three analogs, is considered to be the reason for the preference of other biotransformations. Another fentanyl analog with different major metabolites is butyrylfentanyl, which is mainly metabolized in vivo by hydroxylation and carboxylation on the butyryl side chain [34]. Surprisingly, this side chain, which is only one carbon atom longer than fentanyl's, seems to have changed the metabolic profile. 


\section{Conclusion}

Given the great number of possible structural variations and the current phenomenon of constantly emerging new psychoactive substances, more 'new' fentanyl analogs are likely to appear. Taken together our results, we consider it legitimate to - initially-predict metabolites of newly emerged fentanyl analogs based on current knowledge about the metabolism of known fentanyl analogs. Likely, the nor-metabolite, one or several hydroxy metabolites and/or a hydroxymethoxy metabolite will be prevalent. However, as some analogs can show a significantly different metabolism, we consider it crucial to confirm the predictions with comprehensive metabolite identification studies, if possible with both in vitro and in vivo studies. 


\section{Acknowledgements}

The authors thank Advanced Chemistry Development (ACD/Labs) for providing MetaSense ${ }^{\mathrm{TM}}$ software as well as Richard Lee and Edward Milton for their help. This research was conducted within the Strategic Research Area Forensic Sciences (Strategiområdet Forensiska Vetenskaper) at Linköping University.

\section{Conflicts of interest}

None. 


\section{Legends to Figures}

Fig. 1: Structures of fentanyl and analogs that have approved medicinal use, others that have been abused for several decades and those that appeared recently on the illicit drug market.

Fig. 2: Proposed metabolic pathway of acetylfentanyl combining both human hepatocyte and human urine metabolites. Markush structures are used where the exact position of functional groups cannot be determined. Enclosed metabolites are the major metabolites detected in hydrolyzed human urine samples, metabolite in italics were only found in either the in vitro or in vivo experiment

Fig. 3: Proposed metabolic pathway of acrylfentanyl combining both human hepatocyte and human urine metabolites. Markush structures are used where the exact position of functional groups cannot be determined. Enclosed metabolites are the major metabolites detected in hydrolyzed human urine samples, metabolite in italics were only found in either the in vitro or in vivo experiment.

Fig. 4: Proposed metabolic pathway of 4-fluoro-isobutyrylfentanyl combining both human hepatocyte and human urine metabolites. Markush structures are used where the exact position of functional groups cannot be determined. Enclosed metabolites are the major metabolites detected in hydrolyzed human urine samples, metabolite in italics were only found in either the in vitro or in vivo experiment.

Fig. 5: Proposed metabolic pathway of furanylfentanyl combining both human hepatocyte and human urine metabolites. Markush structures are used where the exact position of functional groups cannot be determined. Enclosed metabolites are the major metabolites detected in hydrolyzed human urine samples, metabolite in italics were only found in either the in vitro or in vivo experiment. 


\section{References}

1. European Monitoring Centre for Drugs and Drug Addiction. EMCDDA-Europol 2015 Annual Report on the implementation of Council Decision 2005/387/JHA2016 26 September 2016. Available from: http://www.emcdda.europa.eu/publications/implementationreports/2015.

2. Chen JC, Smith ER, Cahill M, Cohen R, Fishman JB. The opioid receptor binding of dezocine, morphine, fentanyl, butorphanol and nalbuphine. Life Sci. 1993;52(4):389-96. doi:http://dx.doi.org/10.1016/0024-3205(93)90152-S.

3. Higashikawa Y, Suzuki S. Studies on 1-(2-phenethyl)-4-(N-propionylanilino)piperidine (fentanyl) and its related compounds. VI. Structure-analgesic activity relationship for fentanyl, methyl-substituted fentanyls and other analogues. Forensic Toxicol. 2008;26(1):1-5. doi:10.1007/s11419-007-0039-1.

4. Nelson L, Schwaner R. Transdermal fentanyl: Pharmacology and toxicology. J Med Toxicol. 2009;5(4):230-41. doi:10.1007/bf03178274.

5. Kronstrand R, Druid H, Holmgren P, Rajs J. A cluster of fentanyl-related deaths among drug addicts in Sweden. Forensic Sci Int. 1997;88(3):185-95. doi:http://dx.doi.org/10.1016/S0379-0738(97)00068-6.

6. Vardanyan RS, Hruby VJ. Fentanyl-related compounds and derivatives: current status and future prospects for pharmaceutical applications. Future Med Chem. 2014;6(4):385-412. doi:10.4155/fmc.13.215.

7. Henderson G. Designer Drugs: Past History and Future Prospects. J Forensic Sci. 1988;33(2):569-75. doi: https://doi.org/10.1520/JFS11976J.

8. Helander A, Backberg M, Beck O. Intoxications involving the fentanyl analogs acetylfentanyl, 4-methoxybutyrfentanyl and furanylfentanyl: results from the Swedish STRIDA project. Clin Toxicol (Phila). 2016;54(4):324-32. doi:10.3109/15563650.2016.1139715.

9. Backberg $\mathrm{M}$, Beck $\mathrm{O}$, Jonsson $\mathrm{KH}$, Helander $\mathrm{A}$. Opioid intoxications involving butyrfentanyl, 4-fluorobutyrfentanyl, and fentanyl from the Swedish STRIDA project. Clin Toxicol (Phila). 2015;53(7):609-17. doi:10.3109/15563650.2015.1054505.

10. McClain DA, Hug CC. Intravenous fentanyl kinetics. Clinical Pharmacology \& Therapeutics. 1980;28(1):106-14. doi:10.1038/clpt.1980.138.

11. Goromaru T, Matsuura H, Yoshimura N, Miyawaki T, Sameshima T, Miyao J, et al. Identification and Quantitative Determination of Fentanyl Metabolites in Patients by Gas Chromatography-Mass Spectrometry Anesthesiology. 1984;61(1):73-7.

12. Mahlke NS, Ziesenitz V, Mikus G, Skopp G. Quantitative low-volume assay for simultaneous determination of fentanyl, norfentanyl, and minor metabolites in human plasma and urine by liquid chromatography-tandem mass spectrometry (LC-MS/MS). International journal of legal medicine. 2014;128(5):771-8. doi:10.1007/s00414-014-1040-y.

13. Higashikawa $\mathrm{Y}$, Suzuki S. Studies on 1-(2-Phenethyl)-4-(N-Propionylanilino)Piperidine (Fentanyl) and Its Related Compounds: Novel Metabolites in Rat Urine Following Injection of \& alpha-Methylfentanyl, One of the Most Abused Typical Designer Drugs. Journal of Health Science. 2008;54(6):629-37. doi:10.1248/jhs.54.629.

14. Meyer MR, Dinger J, Schwaninger AE, Wissenbach DK, Zapp J, Fritschi G, et al. Qualitative studies on the metabolism and the toxicological detection of the fentanyl-derived 
designer drugs 3-methylfentanyl and isofentanyl in rats using liquid chromatography-linear ion trap-mass spectrometry (LC-MSn). Anal Bioanal Chem. 2012;402(3):1249-55.

doi:10.1007/s00216-011-5528-8.

15. Staeheli SN, Baumgartner MR, Gauthier S, Gascho D, Jarmer J, Kraemer T, et al. Timedependent postmortem redistribution of butyrfentanyl and its metabolites in blood and alternative matrices in a case of butyrfentanyl intoxication. Forensic Sci Int. 2016;266:170-7. doi:10.1016/j.forsciint.2016.05.034.

16. Patton AL, Seely KA, Pulla S, Rusch NJ, Moran CL, Fantegrossi WE, et al. Quantitative measurement of acetyl fentanyl and acetyl norfentanyl in human urine by LC-MS/MS. Anal Chem. 2014;86(3):1760-6. doi:10.1021/ac4036197.

17. Melent'ev AB, Kataev SS, Dvorskaya ON. Identification and analytical properties of acetyl fentanyl metabolites. J Anal Chem. 2015;70(2):240-8. doi:10.1134/s1061934815020124.

18. Wohlfarth A, Scheidweiler KB, Pang S, Zhu M, Castaneto M, Kronstrand R, et al. Metabolic characterization of $\mathrm{AH}-7921$, a synthetic opioid designer drug: in vitro metabolic stability assessment and metabolite identification, evaluation of in silico prediction, and in vivo confirmation. Drug Test Anal. 2016;8(8):779-91. doi:10.1002/dta.1856.

19. Castaneto MS, Wohlfarth A, Desrosiers NA, Hartman RL, Gorelick DA, Huestis MA. Synthetic cannabinoids pharmacokinetics and detection methods in biological matrices. Drug Metab Rev. 2015;47(2):124-74. doi:10.3109/03602532.2015.1029635.

20. Roman M, Strom L, Tell H, Josefsson M. Liquid chromatography/time-of-flight mass spectrometry analysis of postmortem blood samples for targeted toxicological screening. Anal Bioanal Chem. 2013;405(12):4107-25. doi:10.1007/s00216-013-6798-0.

21. Holcapek $M$, Jirasko $R$, Lisa $M$. Basic rules for the interpretation of atmospheric pressure ionization mass spectra of small molecules. J Chromatogr A. 2010;1217(25):3908-21. doi:10.1016/j.chroma.2010.02.049.

22. Guldberg HC, Marsden CA. Catechol-O-Methyl Transferase: Pharmacological Aspects and Physiological Role. Pharmacological Reviews. 1975;27(2):135-206.

23. Meyer MR, Maurer HH. Enantioselectivity in the Methylation of the Catecholic Phase I Metabolites of Methylenedioxy Designer Drugs and Their Capability To Inhibit Catechol-Omethyltransferase-Catalyzed Dopamine 3-Methylation. Chem Res Toxicol. 2009;22(6):1205-11. doi:10.1021/tx900134e.

24. Testa B, Mayer JM. The Hydration of Epoxides. Hydrolysis in Drug and Prodrug Metabolism: Verlag Helvetica Chimica Acta; 2006. p. 591-661.

25. Nebert DW, Roe AL, Vandale SE, Bingham E, Oakley GG. NAD(P)H:quinone oxidoreductase (NQO1) polymorphism, exposure to benzene, and predisposition to disease: $A$ HuGE review. Genet Med. 2002;4(2):62-70.

26. Sobolevsky T, Prasolov I, Rodchenkov G. Detection of urinary metabolites of AM-2201 and UR-144, two novel synthetic cannabinoids. Drug Test Anal. 2012;4(10):745-53. doi:10.1002/dta.1418.

27. Wohlfarth A, Pang S, Zhu M, Gandhi AS, Scheidweiler KB, Liu HF, et al. First metabolic profile of XLR-11, a novel synthetic cannabinoid, obtained by using human hepatocytes and high-resolution mass spectrometry. Clin Chem. 2013;59(11):1638-48.

doi:10.1373/clinchem.2013.209965. 
28. Feasel MG, Wohlfarth A, Nilles JM, Pang S, Kristovich RL, Huestis MA. Metabolism of Carfentanil, an Ultra-Potent Opioid, in Human Liver Microsomes and Human Hepatocytes by High-Resolution Mass Spectrometry. The AAPS Journal. 2016:1-11. doi:10.1208/s12248-0169963-5.

29. Cashman JR, Park SB, Yang ZC, Wrighton SA, Jacob P, Benowitz NL. Metabolism of nicotine by human liver microsomes: stereoselective formation of trans-nicotine $\mathrm{N}^{\prime}$-oxide. Chem Res Toxicol. 1992;5(5):639-46. doi:10.1021/tx00029a008.

30. Pirmohamed M, Williams D, Madden S, Templeton E, Park BK. Metabolism and bioactivation of clozapine by human liver in vitro. J Pharmacol Exp Ther. 1995;272(3):984-90. 31. Peterson LA. Reactive metabolites in the biotransformation of molecules containing a furan ring. Chem Res Toxicol. 2013;26(1):6-25. doi:10.1021/tx3003824.

32. Kalgutkar AS, Gardner I, Obach RS, Shaffer CL, Callegari E, Henne KR, et al. A Comprehensive Listing of Bioactivation Pathways of Organic Functional Groups. Current Drug Metabolism. 2005;6(3):161-225. doi:http://dx.doi.org/10.2174/1389200054021799.

33. Diao X, Wohlfarth A, Pang S, Scheidweiler KB, Huestis MA. High-Resolution Mass Spectrometry for Characterizing the Metabolism of Synthetic Cannabinoid THJ-018 and Its 5Fluoro Analog THJ-2201 after Incubation in Human Hepatocytes. Clin Chem. 2016;62(1):157-69. doi:10.1373/clinchem.2015.243535.

34. Steuer AE, Williner E, Staeheli S, Kraemer T. Studies on the metabolism of the fentanylderived designer drug butyrfentanyl in human in vitro liver preparations and authentic human samples using liquid chromatography-high resolution mass spectrometry (LC-HRMS). Drug Test Anal. 2016:(in press). doi:10.1002/dta.2111. 
Table 1: Acetylfentanyl metabolites with proposed biotransformation, retention time, elemental composition, accurate mass of protonated molecule, mass error of proposed metabolite, MS peak areas in hepatocyte samples ( $0 \mathrm{~h}, 1 \mathrm{~h}, 3 \mathrm{~h}$ and $5 \mathrm{~h}$ ) and in five urine samples (hydrolyzed and non-hydrolyzed), and diagnostic product ions (masses and mass errors taken from sample \#3, and \#5 in case of saturation).

\begin{tabular}{|c|c|c|c|c|c|c|c|c|c|c|c|c|c|c|c|}
\hline \multirow[b]{2}{*}{ ID } & \multirow[b]{2}{*}{ Biotransformation } & \multirow[b]{2}{*}{$\begin{array}{c}\mathrm{RT} \\
(\mathrm{min})\end{array}$} & \multirow[b]{2}{*}{$\begin{array}{l}\text { Elemental } \\
\text { composition }\end{array}$} & \multirow[b]{2}{*}{$m / z$} & \multirow[b]{2}{*}{$\begin{array}{l}\text { mass } \\
\text { error } \\
(\mathrm{ppm})\end{array}$} & \multicolumn{4}{|c|}{ Peak areas in the hepatocyte samples } & \multicolumn{5}{|c|}{ Peak areas in the urine samples } & \multirow[b]{2}{*}{$\begin{array}{l}\text { Diagnostic } \\
\text { ions }\end{array}$} \\
\hline & & & & & & Oh & 1h & $3 h$ & $5 \mathrm{~h}$ & $\begin{array}{c}\# 1 \\
\text { HYD } \\
\text { NON-HYD }\end{array}$ & $\begin{array}{c}\# 2 \\
\text { HYD } \\
\text { NON-HYD }\end{array}$ & $\begin{array}{c}\# 3 \\
\text { HYD } \\
\text { NON-HYD }\end{array}$ & $\begin{array}{c}\# 4 \\
\text { HYD } \\
\text { NON-HYD }\end{array}$ & $\begin{array}{c}\# 5 \\
\text { HYD } \\
\text { NON-HYD }\end{array}$ & \\
\hline & Blood acetylfentany & concent & ation (in $\mu \mathrm{g} / \mathrm{g}$ ) & & & & & & & 0.77 & 0.17 & 0.18 & 0.04 & 0.02 & \\
\hline \multirow[t]{2}{*}{ A1 } & $\begin{array}{l}\mathrm{N} \text {-dealkylation + } \\
\text { hydroxylation }\end{array}$ & 2.77 & $\mathrm{C}_{13} \mathrm{H}_{18} \mathrm{~N}_{2} \mathrm{O}_{2}$ & 235.1441 & 0.08 & ND & ND & ND & ND & $1.0 \mathrm{E}+06$ & ND & $1.9 \mathrm{E}+05$ & ND & ND & 84.0809 \\
\hline & & & & & & & & & & ND & ND & $1.7 \mathrm{E}+05$ & ND & ND & \\
\hline \multirow[t]{2}{*}{ A2 } & $\begin{array}{l}N \text {-dealkylation + } \\
\text { hydroxylation }\end{array}$ & 2.93 & $\mathrm{C}_{13} \mathrm{H}_{18} \mathrm{~N}_{2} \mathrm{O}_{2}$ & 235.1444 & 2.24 & ND & ND & ND & ND & $3.6 \mathrm{E}+05$ & ND & $1.1 \mathrm{E}+05$ & ND & ND & 84.0803 \\
\hline & & & & & & & & & & $2.7 \mathrm{E}+05$ & ND & $6.9 \mathrm{E}+04$ & ND & ND & \\
\hline \multirow[t]{2}{*}{ A3 } & $\begin{array}{l}\mathrm{N} \text {-dealkylation } \\
\text { (yielding nor- } \\
\text { metabolite) }\end{array}$ & 4.19 & $\mathrm{C}_{13} \mathrm{H}_{18} \mathrm{~N}_{2} \mathrm{O}$ & 219.1490 & -0.89 & $4.6 \mathrm{E}+05$ & $2.1 \mathrm{E}+06$ & $4.4 \mathrm{E}+06$ & $5.6 \mathrm{E}+06$ & $2.5 \mathrm{E}+07$ & $2.9 \mathrm{E}+06$ & $1.8 \mathrm{E}+07$ & $2.3 \mathrm{E}+05$ & $2.3 \mathrm{E}+06$ & $\begin{array}{l}84.0805, \\
94.0645 \\
136.0750\end{array}$ \\
\hline & & & & & & & & & & $2.4 \mathrm{E}+07$ & $3.0 \mathrm{E}+06$ & $1.7 \mathrm{E}+07$ & $2.3 \mathrm{E}+05$ & $2.4 \mathrm{E}+06$ & \\
\hline \multirow[t]{2}{*}{ A4 } & $\begin{array}{l}\text { Dihydrodiol } \\
\text { formation } \\
\text { (ethylphenyl) }\end{array}$ & 4.66 & $\mathrm{C}_{21} \mathrm{H}_{28} \mathrm{~N}_{2} \mathrm{O}_{3}$ & 357.2195 & 4.22 & ND & $7.1 \mathrm{E}+05$ & $1.2 \mathrm{E}+06$ & $1.7 \mathrm{E}+06$ & $1.7 \mathrm{E}+07$ & $4.6 \mathrm{E}+05$ & $1.0 \mathrm{E}+07$ & $5.1 \mathrm{E}+04$ & $3.7 \mathrm{E}+05$ & $\begin{array}{l}121.0644, \\
146.0962, \\
158.0952, \\
188.1071, \\
204.1374, \\
222.1462\end{array}$ \\
\hline & & & & & & & & & & $1.6 \mathrm{E}+07$ & $4.4 \mathrm{E}+05$ & $9.5 \mathrm{E}+06$ & ND & $3.2 \mathrm{E}+05$ & \\
\hline \multirow[t]{2}{*}{ A5 } & $\begin{array}{l}\text { Dihydroxylation + } \\
\text { Glucuronidation }\end{array}$ & 4.74 & $\mathrm{C}_{27} \mathrm{H}_{34} \mathrm{~N}_{2} \mathrm{O}_{9}$ & 531.2339 & 0.15 & ND & ND & ND & ND & ND & ND & ND & ND & ND & $\begin{array}{l}91.0532, \\
119.0475, \\
137.0595, \\
220.1317, \\
355.2043\end{array}$ \\
\hline & & & & & & & & & & $1.8 \mathrm{E}+06$ & ND & $3.6 \mathrm{E}+05$ & ND & $3.4 \mathrm{E}+04$ & \\
\hline
\end{tabular}




\begin{tabular}{|c|c|c|c|c|c|c|c|c|c|c|c|c|c|c|c|}
\hline A6 & $\begin{array}{l}\text { Hydroxylation + } \\
\text { Glucuronidation }\end{array}$ & 4.79 & $\mathrm{C}_{27} \mathrm{H}_{34} \mathrm{~N}_{2} \mathrm{O}_{8}$ & 515.2380 & -2.04 & ND & ND & ND & $1.0 \mathrm{E}+04$ & $2.9 E+06$ & ND & $2.2 \mathrm{E}+04$ & ND & ND & $\begin{array}{l}84.0808, \\
121.0641, \\
204.1379\end{array}$ \\
\hline & & & & & & & & & & $2.8 \mathrm{E}+07$ & $7.4 \mathrm{E}+05$ & $1.7 \mathrm{E}+07$ & $7.1 \mathrm{E}+04$ & $1.3 \mathrm{E}+06$ & \\
\hline \multirow[t]{2}{*}{ A7 } & $\begin{array}{l}\text { Dihydrodiol } \\
\text { formation ( } N \text { - } \\
\text { phenyl) }\end{array}$ & 4.85 & $\mathrm{C}_{21} \mathrm{H}_{28} \mathrm{~N}_{2} \mathrm{O}_{3}$ & 357.2170 & -0.94 & ND & ND & ND & ND & $1.8 \mathrm{E}+06$ & ND & $3.5 \mathrm{E}+05$ & ND & ND & $\begin{array}{l}105.0697, \\
188.1436\end{array}$ \\
\hline & & & & & & & & & & $2.1 \mathrm{E}+06$ & ND & $3.9 \mathrm{E}+05$ & ND & ND & \\
\hline \multirow[t]{2}{*}{ A8 } & Dihydroxylation & 4.92 & $\mathrm{C}_{21} \mathrm{H}_{26} \mathrm{~N}_{2} \mathrm{O}_{3}$ & 355.2013 & -3.27 & ND & ND & ND & ND & $8.6 \mathrm{E}+05$ & ND & $1.9 \mathrm{E}+05$ & ND & $4.1 \mathrm{E}+04$ & $\begin{array}{l}84.0806, \\
121.0648, \\
204.0378\end{array}$ \\
\hline & & & & & & & & & & $1.9 \mathrm{E}+05$ & ND & $5.1 \mathrm{E}+04$ & ND & ND & \\
\hline \multirow[t]{2}{*}{ A9 } & $\begin{array}{l}\text { Dihydroxylation + } \\
\text { Methylation + } \\
\text { Glucuronidation }\end{array}$ & 4.97 & $\mathrm{C}_{28} \mathrm{H}_{36} \mathrm{~N}_{2} \mathrm{O}_{9}$ & 545.2526 & 3.87 & ND & ND & ND & ND & ND & ND & $\mathrm{ND}$ & ND & ND & $\begin{array}{l}84.0808, \\
119.0486, \\
151.0749, \\
234.1486\end{array}$ \\
\hline & & & & & & & & & & $2.6 \mathrm{E}+07$ & $5.6 \mathrm{E}+05$ & $1.5 \mathrm{E}+07$ & $1.7 E+05$ & $1.8 \mathrm{E}+06$ & \\
\hline \multirow[t]{2}{*}{ A10 } & $\begin{array}{l}\text { Dihydroxylation + } \\
\text { Glucuronidation }\end{array}$ & 5.10 & $\mathrm{C}_{27} \mathrm{H}_{34} \mathrm{~N}_{2} \mathrm{O}_{9}$ & 531.2333 & -0.4 & ND & ND & ND & ND & ND & ND & ND & ND & ND & $\begin{array}{l}84.0802, \\
119.0473, \\
137.0586, \\
220.1319, \\
355.1995\end{array}$ \\
\hline & & & & & & & & & & $3.7 E+06$ & ND & $1.1 \mathrm{E}+06$ & ND & $8.6 \mathrm{E}+04$ & \\
\hline \multirow[t]{2}{*}{ A11 } & $\begin{array}{l}\text { Hydroxylation + } \\
\text { Glucuronidation }\end{array}$ & 5.17 & $\mathrm{C}_{27} \mathrm{H}_{34} \mathrm{~N}_{2} \mathrm{O}_{8}$ & 515.2383 & -0.65 & ND & ND & ND & ND & ND & ND & ND & ND & ND & $\begin{array}{l}121.0644, \\
204.1379, \\
339.2073\end{array}$ \\
\hline & & & & & & & & & & $4.0 E+06$ & $6.7 E+04$ & $8.9 E+05$ & ND & $3.6 \mathrm{E}+04$ & \\
\hline \multirow[t]{2}{*}{ A12 } & $\begin{array}{l}\text { Dihydroxylation + } \\
\text { Methylation + } \\
\text { Glucuronidation }\end{array}$ & 5.55 & $\mathrm{C}_{28} \mathrm{H}_{36} \mathrm{~N}_{2} \mathrm{O}_{9}$ & 545.249 & -0.52 & ND & ND & ND & ND & ND & ND & ND & ND & ND & $\begin{array}{l}119.0487, \\
151.0752, \\
192.0989 \\
234.1476\end{array}$ \\
\hline & & & & & & & & & & $2.4 \mathrm{E}+06$ & $1.6 \mathrm{E}+04$ & $5.9 \mathrm{E}+05$ & ND & $5.6 \mathrm{E}+04$ & \\
\hline A13 & Dihydroxylation & 5.60 & $\mathrm{C}_{21} \mathrm{H}_{26} \mathrm{~N}_{2} \mathrm{O}_{3}$ & 355.2018 & 0.46 & ND & ND & ND & ND & $1.2 \mathrm{E}+06$ & ND & $2.7 E+05$ & ND & ND & $\begin{array}{l}107.0491, \\
121.0630, \\
188.1064,\end{array}$ \\
\hline
\end{tabular}

26 | P a g e 


\begin{tabular}{|c|c|c|c|c|c|c|c|c|c|c|c|c|c|c|c|}
\hline & & & & & & & & & & & & & & & $\begin{array}{l}\text { 202.1230, } \\
337.1857\end{array}$ \\
\hline & & & & & & & & & & $6.6 \mathrm{E}+05$ & ND & $9.7 \mathrm{E}+04$ & ND & ND & \\
\hline \multirow[t]{2}{*}{ A14 } & Dihydroxylation & 5.72 & $\mathrm{C}_{21} \mathrm{H}_{26} \mathrm{~N}_{2} \mathrm{O}_{3}$ & 355.2012 & -1.12 & ND & ND & ND & ND & $2.1 \mathrm{E}+07$ & $6.5 \mathrm{E}+05$ & $1.6 \mathrm{E}+07$ & $1.5 \mathrm{E}+05$ & $2.5 \mathrm{E}+06$ & $\begin{array}{l}11.0539, \\
119.0488, \\
137.0595, \\
220.1330\end{array}$ \\
\hline & & & & & & & & & & $5.3 \mathrm{E}+06$ & $1.4 \mathrm{E}+05$ & $7.4 \mathrm{E}+06$ & ND & $2.5 \mathrm{E}+05$ & \\
\hline \multirow[t]{2}{*}{ A15 } & $\begin{array}{l}\text { Carbonylation + } \\
\text { Hydroxylation }\end{array}$ & 5.74 & $\mathrm{C}_{21} \mathrm{H}_{24} \mathrm{~N}_{2} \mathrm{O}_{3}$ & 353.1854 & -1.11 & ND & ND & ND & ND & $7.3 \mathrm{E}+06$ & $3.6 \mathrm{E}+04$ & $9.8 \mathrm{E}+05$ & ND & $1.9 \mathrm{E}+05$ & $\begin{array}{l}118.0647 \\
132.0806, \\
164.0705, \\
202.1221, \\
218.1167 \\
\end{array}$ \\
\hline & & & & & & & & & & $8.1 \mathrm{E}+06$ & $4.2 \mathrm{E}+04$ & $1.1 \mathrm{E}+06$ & ND & $2.4 \mathrm{E}+05$ & \\
\hline \multirow[t]{2}{*}{ A16 } & $\begin{array}{l}\text { Hydroxylation + } \\
\text { Amide hydrolysis }\end{array}$ & 5.75 & $\mathrm{C}_{19} \mathrm{H}_{24} \mathrm{~N}_{2} \mathrm{O}$ & 297.1959 & -1.05 & ND & ND & ND & ND & ND & ND & $3.8 \mathrm{E}+05$ & ND & $5.1 \mathrm{E}+04$ & $\begin{array}{l}105.0689 \\
188.1416\end{array}$ \\
\hline & & & & & & & & & & ND & ND & ND & ND & ND & \\
\hline \multirow[t]{2}{*}{ A17 } & $\begin{array}{l}\text { Hydroxylation + } \\
\text { Sulfation }\end{array}$ & 5.87 & $\mathrm{C}_{21} \mathrm{H}_{26} \mathrm{~N}_{2} \mathrm{O}_{5} \mathrm{~S}$ & 419.1634 & -0.78 & ND & ND & ND & ND & $1.2 \mathrm{E}+06$ & ND & $2.5 \mathrm{E}+05$ & ND & ND & $\begin{array}{l}\text { 103.0530, } \\
121.0650, \\
204.1380\end{array}$ \\
\hline & & & & & & & & & & $1.2 \mathrm{E}+06$ & ND & $2.5 \mathrm{E}+05$ & ND & ND & \\
\hline \multirow[t]{2}{*}{ A18 } & $\begin{array}{l}\text { Carbonylation + } \\
\text { Hydroxylation }\end{array}$ & 5.88 & $\mathrm{C}_{21} \mathrm{H}_{24} \mathrm{~N}_{2} \mathrm{O}_{3}$ & 353.1852 & -1.94 & ND & $2.4 \mathrm{E}+04$ & $2.8 \mathrm{E}+04$ & $2.5 \mathrm{E}+04$ & $7.1 \mathrm{E}+06$ & $2.3 \mathrm{E}+04$ & $8.8 \mathrm{E}+05$ & ND & $1.9 \mathrm{E}+05$ & $\begin{array}{l}118.0651, \\
132.0806, \\
164.0704, \\
202.1215\end{array}$ \\
\hline & & & & & & & & & & $8.0 \mathrm{E}+06$ & $2.5 \mathrm{E}+04$ & $1.1 \mathrm{E}+06$ & ND & $2.1 \mathrm{E}+05$ & \\
\hline \multirow[t]{2}{*}{ A19 } & Dihydroxylation & 5.89 & $\mathrm{C}_{21} \mathrm{H}_{26} \mathrm{~N}_{2} \mathrm{O}_{3}$ & 355.2010 & -2.56 & ND & ND & ND & ND & $3.2 \mathrm{E}+06$ & ND & $1.3 \mathrm{E}+06$ & ND & $5.5 \mathrm{E}+04$ & $\begin{array}{l}91.0540, \\
105.0694, \\
188.1433\end{array}$ \\
\hline & & & & & & & & & & $6.4 \mathrm{E}+05$ & ND & $3.0 \mathrm{E}+05$ & ND & ND & \\
\hline \multirow[t]{2}{*}{ A20 } & $\begin{array}{l}\text { Hydroxylation + } \\
\text { Glucuronidation }\end{array}$ & 5.90 & $\mathrm{C}_{27} \mathrm{H}_{34} \mathrm{~N}_{2} \mathrm{O}_{8}$ & 515.2380 & -1.85 & ND & ND & ND & ND & $7.4 \mathrm{E}+05$ & ND & $7.9 \mathrm{E}+04$ & ND & ND & $\begin{array}{l}186.1280 \\
321.1947\end{array}$ \\
\hline & & & & & & & & & & $1.1 \mathrm{E}+06$ & ND & $7.9 \mathrm{E}+04$ & ND & ND & \\
\hline A21 & $\begin{array}{l}\text { Dihydroxylation + } \\
\text { Methylation + } \\
\text { Sulfation }\end{array}$ & 5.93 & $\mathrm{C}_{22} \mathrm{H}_{28} \mathrm{~N}_{2} \mathrm{O}_{6} \mathrm{~S}$ & 449.1741 & 0.14 & ND & ND & ND & ND & ND & ND & ND & ND & ND & $\begin{array}{l}\text { 84.0806, } \\
119.0483,\end{array}$ \\
\hline
\end{tabular}

27 I P g e 


\begin{tabular}{|c|c|c|c|c|c|c|c|c|c|c|c|c|c|c|c|}
\hline & & & & & & & & & & & & & & & $\begin{array}{l}151.0748 \\
234.1476\end{array}$ \\
\hline & & & & & & & & & & $6.0 \mathrm{E}+06$ & $4.5 \mathrm{E}+04$ & $8.6 \mathrm{E}+05$ & ND & $1.2 \mathrm{E}+05$ & \\
\hline \multirow[t]{2}{*}{ A22 } & $\begin{array}{l}\text { Dihydroxylation + } \\
\text { Sulfation }\end{array}$ & 6.12 & $\mathrm{C}_{21} \mathrm{H}_{26} \mathrm{~N}_{2} \mathrm{O}_{6} \mathrm{~S}$ & 435.1582 & -0.21 & ND & ND & ND & ND & ND & ND & ND & ND & ND & $\begin{array}{l}84.0809, \\
137.0581, \\
220.1336\end{array}$ \\
\hline & & & & & & & & & & $7.7 \mathrm{E}+05$ & ND & $1.3 \mathrm{E}+05$ & ND & $5.0 \mathrm{E}+04$ & \\
\hline \multirow[t]{2}{*}{ A23 } & $\begin{array}{l}\text { Hydroxylation + } \\
\text { sulfation }\end{array}$ & 6.26 & $\mathrm{C}_{21} \mathrm{H}_{26} \mathrm{~N}_{2} \mathrm{O}_{5} \mathrm{~S}$ & 419.1629 & -1.41 & ND & ND & ND & ND & ND & ND & ND & ND & ND & $\begin{array}{l}84.0805, \\
121.0636, \\
186.9208, \\
204.1377, \\
339.2067\end{array}$ \\
\hline & & & & & & & & & & $2.5 \mathrm{E}+05$ & ND & $1.0 \mathrm{E}+05$ & ND & ND & \\
\hline \multirow[t]{2}{*}{ A24 } & Hydroxylation & 6.30 & $\mathrm{C}_{21} \mathrm{H}_{26} \mathrm{~N}_{2} \mathrm{O}_{2}$ & 339.2071 & 0.56 & ND & $1.4 \mathrm{E}+06$ & $2.5 \mathrm{E}+06$ & $2.9 \mathrm{E}+06$ & $2.4 \mathrm{E}+07$ & $4.1 \mathrm{E}+06$ & $2.1 \mathrm{E}+07$ & $2.2 \mathrm{E}+05$ & $6.2 \mathrm{E}+06$ & $\begin{array}{l}84.0806, \\
103.0535, \\
121.0643, \\
204.1385\end{array}$ \\
\hline & & & & & & & & & & $1.9 \mathrm{E}+07$ & $8.5 E+05$ & $1.4 \mathrm{E}+07$ & ND & $1.3 \mathrm{E}+06$ & \\
\hline \multirow[t]{2}{*}{ A25 } & Hydroxylation & 6.46 & $\mathrm{C}_{21} \mathrm{H}_{26} \mathrm{~N}_{2} \mathrm{O}_{2}$ & 339.2063 & -1.05 & ND & ND & ND & ND & $5.7 \mathrm{E}+06$ & $3.2 \mathrm{E}+04$ & $8.4 \mathrm{E}+05$ & ND & ND & $\begin{array}{l}105.0696, \\
188.1428\end{array}$ \\
\hline & & & & & & & & & & $2.4 \mathrm{E}+06$ & ND & $3.1 \mathrm{E}+05$ & ND & ND & \\
\hline \multirow[t]{2}{*}{ A26 } & $\begin{array}{l}\text { Dihydroxylation + } \\
\text { Methylation }\end{array}$ & 6.60 & $\mathrm{C}_{22} \mathrm{H}_{28} \mathrm{~N}_{2} \mathrm{O}_{3}$ & 369.2189 & 3.1 & ND & $1.1 \mathrm{E}+05$ & $1.5 \mathrm{E}+05$ & $1.7 \mathrm{E}+05$ & $2.4 \mathrm{E}+07$ & $3.9 \mathrm{E}+06$ & $2.1 \mathrm{E}+07$ & $8.6 \mathrm{E}+05$ & $8.6 \mathrm{E}+06$ & $\begin{array}{l}91.0542, \\
119.0490 \\
151.0758, \\
234.1487\end{array}$ \\
\hline & & & & & & & & & & $1.5 \mathrm{E}+07$ & $4.3 \mathrm{E}+05$ & $1.1 \mathrm{E}+07$ & $9.5 \mathrm{E}+04$ & $1.1 \mathrm{E}+06$ & \\
\hline \multirow[t]{2}{*}{ A27 } & $\begin{array}{l}\text { Dihydroxylation + } \\
\text { Methylation }\end{array}$ & 6.72 & $\mathrm{C}_{22} \mathrm{H}_{28} \mathrm{~N}_{2} \mathrm{O}_{3}$ & 369.2168 & -1.28 & ND & ND & ND & ND & $2.5 \mathrm{E}+06$ & ND & $4.4 \mathrm{E}+05$ & ND & $4.8 \mathrm{E}+04$ & $\begin{array}{l}84.0807, \\
105.0698, \\
188.1426\end{array}$ \\
\hline & & & & & & & & & & $2.6 \mathrm{E}+05$ & ND & $5.8 \mathrm{E}+04$ & ND & ND & \\
\hline \multirow[t]{2}{*}{ A28 } & Hydroxylation & 6.74 & $\mathrm{C}_{21} \mathrm{H}_{26} \mathrm{~N}_{2} \mathrm{O}_{2}$ & 339.2063 & -0.81 & ND & ND & ND & ND & $4.9 \mathrm{E}+06$ & $3.5 \mathrm{E}+04$ & $7.7 \mathrm{E}+05$ & ND & ND & $\begin{array}{l}105.0697 \\
188.1430\end{array}$ \\
\hline & & & & & & & & & & $9.2 \mathrm{E}+05$ & ND & ND & ND & ND & \\
\hline A29 & $\begin{array}{l}\text { Dihydroxylation + } \\
\text { Methylation }\end{array}$ & 6.87 & $\mathrm{C}_{22} \mathrm{H}_{28} \mathrm{~N}_{2} \mathrm{O}_{3}$ & 369.2183 & 1.91 & ND & ND & ND & ND & $1.2 \mathrm{E}+07$ & $2.2 \mathrm{E}+05$ & $7.9 E+06$ & $7.2 \mathrm{E}+04$ & $7.9 \mathrm{E}+05$ & $\begin{array}{l}\text { 91.0540, } \\
119.0488,\end{array}$ \\
\hline
\end{tabular}

28| Page 


\begin{tabular}{|c|c|c|c|c|c|c|c|c|c|c|c|c|c|c|c|}
\hline & & & & & & & & & & & & & & & $\begin{array}{l}151.0750, \\
234.1477\end{array}$ \\
\hline & & & & & & & & & & $2.8 \mathrm{E}+05$ & ND & $1.5 \mathrm{E}+05$ & ND & ND & \\
\hline \multirow[t]{2}{*}{ A30 } & Hydroxylation & 7.00 & $\mathrm{C}_{21} \mathrm{H}_{26} \mathrm{~N}_{2} \mathrm{O}_{2}$ & 339.2063 & -1.21 & ND & $2.9 \mathrm{E}+05$ & $5.9 \mathrm{E}+05$ & $7.3 \mathrm{E}+05$ & $1.2 \mathrm{E}+07$ & $1.1 \mathrm{E}+05$ & $2.7 \mathrm{E}+06$ & ND & ND & $\begin{array}{l}91.0537, \\
105.0691, \\
132.0806, \\
186.1278, \\
204.1392\end{array}$ \\
\hline & & & & & & & & & & $1.1 \mathrm{E}+07$ & $9.8 \mathrm{E}+04$ & $1.5 \mathrm{E}+06$ & ND & ND & \\
\hline \multirow[t]{2}{*}{ A31 } & $\begin{array}{l}\text { Hydroxylation + } \\
\text { Amide hydrolysis }\end{array}$ & 7.24 & $\mathrm{C}_{19} \mathrm{H}_{24} \mathrm{~N}_{2} \mathrm{O}$ & 297.1954 & -3.92 & ND & ND & ND & ND & $9.8 \mathrm{E}+04$ & ND & $6.9 \mathrm{E}+04$ & ND & 4.7E+04 & $\begin{array}{l}103.0545, \\
121.0637\end{array}$ \\
\hline & & & & & & & & & & $8.5 \mathrm{E}+04$ & ND & $4.6 \mathrm{E}+04$ & ND & $3.8 \mathrm{E}+04$ & \\
\hline \multirow[t]{2}{*}{$\mathbf{P}$} & Acetylfentanyl & 7.92 & $\mathrm{C}_{21} \mathrm{H}_{26} \mathrm{~N}_{2} \mathrm{O}$ & 323.2120 & 0.49 & $2.5 \mathrm{E}+07$ & $2.4 \mathrm{E}+07$ & $2.2 \mathrm{E}+07$ & $2.1 \mathrm{E}+07$ & $2.5 \mathrm{E}+07$ & $1.7 \mathrm{E}+07$ & $2.1 \mathrm{E}+07$ & $6.7 \mathrm{E}+05$ & $4.3 \mathrm{E}+06$ & $\begin{array}{c}105.0697, \\
132.0801, \\
188.1434\end{array}$ \\
\hline & & & & & & & & & & $2.6 \mathrm{E}+07$ & $1.7 \mathrm{E}+07$ & $2.1 \mathrm{E}+07$ & $7.3 E+05$ & $4.8 \mathrm{E}+06$ & \\
\hline \multirow[t]{2}{*}{ A32 } & Amide hydrolysis & 9.09 & $\mathrm{C}_{19} \mathrm{H}_{24} \mathrm{~N}_{2}$ & 281.2009 & -1.19 & ND & ND & ND & ND & $3.8 \mathrm{E}+05$ & ND & $2.7 \mathrm{E}+06$ & ND & $4.9 \mathrm{E}+05$ & $\begin{array}{l}105.0696 \\
134.0955 \\
188.1423\end{array}$ \\
\hline & & & & & & & & & & $4.0 \mathrm{E}+04$ & ND & $2.9 \mathrm{E}+06$ & ND & $5.5 \mathrm{E}+05$ & \\
\hline
\end{tabular}

HYD: hydrolyzed; NON-HYD: non-hydrolyzed; ND: Not detected; RT: retention time, P: parent compound 
Table 2: Acrylfentanyl metabolites with proposed biotransformation, retention time, elemental composition, accurate mass of protonated molecule, mass error of proposed metabolite, MS peak areas in hepatocyte samples ( $0 \mathrm{~h}, 1 \mathrm{~h}, 3 \mathrm{~h}$ and $5 \mathrm{~h}$ ) and in five urine samples (hydrolyzed and non-hydrolyzed), and diagnostic product ions (masses and mass errors generally taken from sample \#3, except for B12 (\#2), B1 and B14 (\#5) and B10 (hepatocytes).

\begin{tabular}{|c|c|c|c|c|c|c|c|c|c|c|c|c|c|c|c|}
\hline \multirow[b]{2}{*}{ ID } & \multirow[b]{2}{*}{ Biotransformation } & \multirow[b]{2}{*}{$\begin{array}{l}\text { RT } \\
(\min )\end{array}$} & \multirow[b]{2}{*}{$\begin{array}{l}\text { Elemental } \\
\text { composition }\end{array}$} & \multirow[b]{2}{*}{$m / z$} & \multirow[b]{2}{*}{$\begin{array}{l}\text { mass } \\
\text { error } \\
(\mathrm{ppm})\end{array}$} & \multicolumn{4}{|c|}{ Peak areas in the hepatocyte samples } & \multicolumn{5}{|c|}{ Peak areas in the urine samples } & \multirow[b]{2}{*}{$\begin{array}{l}\text { Diagnostic } \\
\text { ions }\end{array}$} \\
\hline & & & & & & Oh & 1h & $3 \mathbf{h}$ & $5 \mathrm{~h}$ & $\begin{array}{c}\# 1 \\
\text { HYD } \\
\text { NON-HYD }\end{array}$ & $\begin{array}{c}\# 2 \\
\text { HYD } \\
\text { NON-HYD }\end{array}$ & $\begin{array}{c}\# 3 \\
\text { HYD } \\
\text { NON- } \\
\text { HYD }\end{array}$ & $\begin{array}{c}\# 4 \\
\text { HYD } \\
\text { NON-HYD }\end{array}$ & $\begin{array}{c}\text { \#5 } \\
\text { HYD } \\
\text { NON-HYD }\end{array}$ & \\
\hline & Blood acrylfentanyl c & nncentr & tion (in $\mathrm{ng} / \mathrm{g}$ ) & & & & & & & 0.06 & 1.20 & 0.10 & 0.05 & 0.11 & \\
\hline \multirow[t]{2}{*}{ B1 } & $\begin{array}{l}N \text {-Dealkylation } \\
\text { (yielding nor- } \\
\text { metabolite) }\end{array}$ & 5.25 & $\mathrm{C}_{14} \mathrm{H}_{18} \mathrm{~N}_{2} \mathrm{O}$ & 231.1503 & 4.48 & $5.0 \mathrm{E}+04$ & $3.5 \mathrm{E}+06$ & $6.5 \mathrm{E}+06$ & $8.2 \mathrm{E}+06$ & $2.0 \mathrm{E}+06$ & $3.2 \mathrm{E}+05$ & $1.3 \mathrm{E}+07$ & $2.1 \mathrm{E}+06$ & $5.1 \mathrm{E}+06$ & 84.0804 \\
\hline & & & & & & & & & & $1.5 \mathrm{E}+06$ & $2.1 \mathrm{E}+05$ & $1.1 \mathrm{E}+07$ & $1.2 \mathrm{E}+06$ & $3.4 \mathrm{E}+06$ & \\
\hline \multirow[t]{2}{*}{ B2 } & $\begin{array}{l}\text { Dihydrodiol } \\
\text { formation (at } \\
\text { ethylphenyl) }\end{array}$ & 5.65 & $\mathrm{C}_{22} \mathrm{H}_{28} \mathrm{~N}_{2} \mathrm{O}_{3}$ & 369.2172 & -0.09 & $\mathrm{ND}$ & $1.3 \mathrm{E}+05$ & $2.2 \mathrm{E}+05$ & $2.6 \mathrm{E}+05$ & $7.2 \mathrm{E}+05$ & $3.5 \mathrm{E}+05$ & $2.4 \mathrm{E}+06$ & $1.2 \mathrm{E}+05$ & $6.2 \mathrm{E}+05$ & $\begin{array}{l}121.0648, \\
146.0966, \\
158.0957, \\
200.1067\end{array}$ \\
\hline & & & & & & & & & & $3.4 \mathrm{E}+05$ & ND & $4.9 \mathrm{E}+05$ & $3.7 \mathrm{E}+04$ & $1.3 \mathrm{E}+05$ & \\
\hline \multirow[t]{2}{*}{ B3 } & $\begin{array}{l}\text { Hydroxylation (at } \\
\text { ethyl) + } \\
\text { Glucuronidation }\end{array}$ & 5.78 & $\mathrm{C}_{28} \mathrm{H}_{34} \mathrm{~N}_{2} \mathrm{O}_{8}$ & 527.2381 & -0.93 & ND & ND & ND & ND & ND & ND & $3.4 \mathrm{E}+05$ & ND & ND & $\begin{array}{l}103.0546, \\
121.0646, \\
204.1361, \\
351.2007\end{array}$ \\
\hline & & & & & & & & & & $1.3 \mathrm{E}+05$ & $1.3 \mathrm{E}+05$ & $7.9 \mathrm{E}+05$ & $2.4 \mathrm{E}+04$ & $3.0 \mathrm{E}+05$ & \\
\hline \multirow[t]{2}{*}{ B4 } & $\begin{array}{l}\text { Dihydroxylation + } \\
\text { Methylation + } \\
\text { Glucuronidation }\end{array}$ & 5.92 & $\mathrm{C}_{29} \mathrm{H}_{36} \mathrm{~N}_{2} \mathrm{O}_{9}$ & 557.2497 & 0.97 & ND & ND & ND & ND & ND & ND & $2.1 \mathrm{E}+05$ & ND & ND & $\begin{array}{l}91.0559, \\
151.0762, \\
234.1470\end{array}$ \\
\hline & & & & & & & & & & $6.5 \mathrm{E}+04$ & $1.2 \mathrm{E}+05$ & $4.5 \mathrm{E}+05$ & ND & $9.6 \mathrm{E}+04$ & \\
\hline B5 & $\begin{array}{l}\text { Dihydroxylation (at } \\
\text { ethylphenyl) + } \\
\text { Glucuronidation }\end{array}$ & 6.01 & $\mathrm{C}_{28} \mathrm{H}_{34} \mathrm{~N}_{2} \mathrm{O}_{9}$ & 543.2338 & 0.29 & ND & ND & ND & ND & ND & ND & ND & ND & ND & $\begin{array}{l}\text { 84.0813, } \\
137.0599, \\
220.1343\end{array}$ \\
\hline
\end{tabular}




\begin{tabular}{|c|c|c|c|c|c|c|c|c|c|c|c|c|c|c|c|}
\hline B6 & $\begin{array}{l}\text { Dihydrodiol } \\
\text { formation ( } N \text { - } \\
\text { phenyl ring) }\end{array}$ & 6.01 & $\mathrm{C}_{22} \mathrm{H}_{28} \mathrm{~N}_{2} \mathrm{O}_{3}$ & 369.2175 & 0.55 & ND & $1.9 \mathrm{E}+05$ & $4.8 \mathrm{E}+05$ & $7.3 \mathrm{E}+05$ & $3.5 \mathrm{E}+05$ & $7.4 \mathrm{E}+05$ & $3.0 \mathrm{E}+06$ & $7.4 \mathrm{E}+05$ & $2.6 \mathrm{E}+06$ & $\begin{array}{l}105.0696, \\
188.1428\end{array}$ \\
\hline & & & & & & & & & & $2.3 \mathrm{E}+05$ & ND & $1.3 \mathrm{E}+06$ & $2.9 \mathrm{E}+05$ & $1.1 \mathrm{E}+06$ & \\
\hline \multirow[t]{2}{*}{ B7 } & $\begin{array}{l}\text { Dihydroxylation (at } \\
\mathrm{N} \text {-phenyl or acryl } \\
\text { moiety) }\end{array}$ & 6.53 & $\mathrm{C}_{22} \mathrm{H}_{26} \mathrm{~N}_{2} \mathrm{O}_{3}$ & 367.2022 & 1.6 & ND & ND & ND & ND & ND & ND & $1.7 \mathrm{E}+05$ & ND & ND & $\begin{array}{l}\text { 105.0695, } \\
188.1441\end{array}$ \\
\hline & & & & & & & & & & ND & ND & ND & ND & ND & \\
\hline \multirow[t]{2}{*}{ B8 } & $\begin{array}{l}\text { Dihydroxylation (at } \\
\text { phenethyl moiety) }\end{array}$ & 6.72 & $\mathrm{C}_{22} \mathrm{H}_{26} \mathrm{~N}_{2} \mathrm{O}_{3}$ & 367.2028 & 2.54 & ND & ND & ND & ND & $8.1 \mathrm{E}+05$ & $3.3 \mathrm{E}+05$ & $5.6 \mathrm{E}+06$ & $1.3 \mathrm{E}+05$ & $1.5 \mathrm{E}+06$ & $\begin{array}{l}84.0807, \\
91.0541, \\
119.0485, \\
137.0597, \\
220.1330\end{array}$ \\
\hline & & & & & & & & & & $7.8 \mathrm{E}+04$ & $6.8 \mathrm{E}+04$ & $9.9 \mathrm{E}+05$ & ND & $5.9 \mathrm{E}+04$ & \\
\hline \multirow[t]{2}{*}{ B9 } & $\begin{array}{l}\text { Hydroxylation (at } \\
\text { ethyl) }\end{array}$ & 7.28 & $\mathrm{C}_{22} \mathrm{H}_{26} \mathrm{~N}_{2} \mathrm{O}_{2}$ & 351.2075 & 1.8 & ND & $4.2 \mathrm{E}+05$ & $6.6 \mathrm{E}+05$ & $8.6 \mathrm{E}+05$ & $1.1 \mathrm{E}+06$ & $1.3 \mathrm{E}+06$ & $5.4 \mathrm{E}+06$ & $3.8 \mathrm{E}+05$ & $3.5 \mathrm{E}+06$ & $\begin{array}{l}103.0541, \\
121.0646, \\
204.1384\end{array}$ \\
\hline & & & & & & & & & & $1.1 \mathrm{E}+05$ & $1.5 \mathrm{E}+05$ & $3.3 \mathrm{E}+05$ & $4.9 \mathrm{E}+04$ & $2.6 \mathrm{E}+05$ & \\
\hline \multirow[t]{2}{*}{ B10 } & $\begin{array}{l}\text { Hydroxylation (at } \\
\mathrm{N} \text {-phenyl or acryl } \\
\text { moiety) }\end{array}$ & 7.47 & $\mathrm{C}_{22} \mathrm{H}_{26} \mathrm{~N}_{2} \mathrm{O}_{2}$ & 351.2072 & 1.13 & ND & $1.6 \mathrm{E}+05$ & $1.8 \mathrm{E}+05$ & $1.9 \mathrm{E}+05$ & ND & ND & ND & ND & ND & $\begin{array}{l}105.0696, \\
188.1370\end{array}$ \\
\hline & & & & & & & & & & ND & ND & ND & ND & ND & \\
\hline \multirow[t]{2}{*}{ B11 } & $\begin{array}{l}\text { Dihydroxylation + } \\
\text { Methylation (both } \\
\text { at phenyl moiety) }\end{array}$ & 7.54 & $\mathrm{C}_{23} \mathrm{H}_{28} \mathrm{~N}_{2} \mathrm{O}_{3}$ & 381.2174 & 0.33 & ND & $1.7 \mathrm{E}+04$ & $2.6 \mathrm{E}+04$ & $3.3 \mathrm{E}+04$ & $4.6 \mathrm{E}+05$ & $1.0 \mathrm{E}+06$ & $2.9 \mathrm{E}+06$ & $1.1 \mathrm{E}+05$ & $8.1 \mathrm{E}+05$ & $\begin{array}{l}91.0542, \\
119.0493, \\
151.0755\end{array}$ \\
\hline & & & & & & & & & & ND & $7.0 \mathrm{E}+04$ & $1.0 \mathrm{E}+05$ & ND & ND & \\
\hline \multirow[t]{2}{*}{ B12 } & $\begin{array}{l}\text { Dihydroxylation + } \\
\text { Methylation (both } \\
\text { at phenyl moiety) }\end{array}$ & 7.8 & $\mathrm{C}_{23} \mathrm{H}_{28} \mathrm{~N}_{2} \mathrm{O}_{3}$ & 381.2179 & 1.3 & ND & ND & ND & ND & ND & $7.2 \mathrm{E}+04$ & $7.9 \mathrm{E}+04$ & ND & $2.7 \mathrm{E}+04$ & $\begin{array}{l}91.0532, \\
119.0879, \\
151.0736\end{array}$ \\
\hline & & & & & & & & & & ND & ND & ND & ND & ND & \\
\hline \multirow[t]{2}{*}{ B13 } & $\begin{array}{l}\text { Hydroxylation (at } \\
\text { piperidinyl) }\end{array}$ & 7.94 & $\mathrm{C}_{22} \mathrm{H}_{26} \mathrm{~N}_{2} \mathrm{O}_{2}$ & 351.2071 & 1.18 & ND & $3.9 \mathrm{E}+05$ & $7.5 \mathrm{E}+05$ & $9.8 \mathrm{E}+05$ & ND & $2.8 \mathrm{E}+04$ & $3.5 \mathrm{E}+05$ & $8.1 \mathrm{E}+04$ & $2.1 \mathrm{E}+05$ & $\begin{array}{l}91.0533, \\
105.0688, \\
186.1282\end{array}$ \\
\hline & & & & & & & & & & ND & ND & $1.3 \mathrm{E}+05$ & ND & $7.4 \mathrm{E}+04$ & \\
\hline $\mathbf{P}$ & Acrylfentanyl & 8.85 & $\mathrm{C}_{22} \mathrm{H}_{26} \mathrm{~N}_{2} \mathrm{O}$ & 335.213 & 2.99 & $2.6 \mathrm{E}+07$ & $2.4 \mathrm{E}+07$ & $2.3 \mathrm{E}+07$ & $2.1 \mathrm{E}+07$ & $8.8 \mathrm{E}+05$ & $1.3 \mathrm{E}+06$ & $6.6 \mathrm{E}+06$ & $2.7 E+06$ & $7.1 \mathrm{E}+06$ & $\begin{array}{l}105.0697, \\
188.1441\end{array}$ \\
\hline
\end{tabular}

31 I $P$ a g 


\begin{tabular}{|c|c|c|c|c|c|c|c|c|c|c|c|c|c|c|c|}
\hline & & & & & & & & & & $7.0 \mathrm{E}+05$ & $9.2 E+05$ & $5.4 \mathrm{E}+06$ & $1.7 \mathrm{E}+06$ & $5.3 E+06$ & \\
\hline \multirow[t]{2}{*}{ B14 } & Amide hydrolysis & 9.06 & $\mathrm{C}_{19} \mathrm{H}_{24} \mathrm{~N}_{2}$ & 281.2015 & 1.09 & ND & $3.1 \mathrm{E}+04$ & $6.4 \mathrm{E}+04$ & $7.2 E+04$ & ND & $1.6 \mathrm{E}+04$ & ND & ND & $9.8 \mathrm{E}+04$ & 105.0687, \\
\hline & & & & & & & & & & & & & & & 188.1433 \\
\hline
\end{tabular}

HYD: hydrolyzed; NON-HYD: non-hydrolyzed; ND: Not detected; RT: retention time, P: parent compound 
Table 3: 4-Fluoro-isobutyrylfentanyl metabolites with proposed biotransformation, retention time, elemental composition, accurate mass of protonated molecule, mass error of proposed metabolite, MS peak areas in hepatocyte samples ( $0 \mathrm{~h}, 1 \mathrm{~h}, 3 \mathrm{~h}$ and $5 \mathrm{~h}$ ) and in five urine samples (hydrolyzed and non-hydrolyzed), and diagnostic product ions (masses and mass errors generally taken from sample \#3, except for C2 (\#1) and C8, C14, C16 and C17 (hepatocytes).

\begin{tabular}{|c|c|c|c|c|c|c|c|c|c|c|c|c|c|c|}
\hline \multirow[b]{2}{*}{ ID } & \multirow[b]{2}{*}{ Biotransformation } & \multirow[b]{2}{*}{ RT } & \multirow[b]{2}{*}{$\begin{array}{l}\text { Elemental } \\
\text { composition }\end{array}$} & \multirow[b]{2}{*}{$m / z$} & \multirow[b]{2}{*}{$\begin{array}{l}\text { mass } \\
\text { error } \\
(\mathrm{ppm})\end{array}$} & \multicolumn{4}{|c|}{ Peak areas in hepatocytes } & \multicolumn{5}{|c|}{ Peak areas in urine samples } \\
\hline & & & & & & Oh & 1h & $3 h$ & $5 \mathrm{~h}$ & $\begin{array}{c}\# 1 \\
\text { HYD } \\
\text { NON-HYD }\end{array}$ & $\begin{array}{c}\# 2 \\
\text { HYD } \\
\text { NON-HYD }\end{array}$ & $\begin{array}{c}\# 3 \\
\text { HYD } \\
\text { NON-HYD }\end{array}$ & $\begin{array}{c}\# 4 \\
\text { HYD } \\
\text { NON-HYD }\end{array}$ & Diagnostic ions \\
\hline & Blood 4-fluoro-isobu & rylfent & nyl concentrati & (in ng/g) & & & & & & 78 & 3.2 & 102 & 46 & \\
\hline \multirow[t]{2}{*}{ C1 } & $\begin{array}{l}\text { Oxidative } N- \\
\text { dealkylation }+ \\
\text { reduction }\end{array}$ & 4.08 & $\mathrm{C}_{13} \mathrm{H}_{19} \mathrm{NO}$ & 206.1543 & -0.57 & ND & ND & ND & ND & $1.2 \mathrm{E}+06$ & ND & $2.3 E+04$ & ND & 105.0698 \\
\hline & & & & & & & & & & $1.1 \mathrm{E}+06$ & ND & $2.2 \mathrm{E}+04$ & ND & \\
\hline \multirow[t]{2}{*}{$\mathbf{C 2}$} & Carboxylation & 6.64 & $\mathrm{C}_{23} \mathrm{H}_{27} \mathrm{FN}_{2} \mathrm{O}_{3}$ & 399.2101 & 5.09 & ND & ND & ND & ND & $1.3 \mathrm{E}+05$ & ND & ND & ND & $\begin{array}{l}105.0689, \\
188.1443\end{array}$ \\
\hline & & & & & & & & & & ND & ND & ND & ND & \\
\hline \multirow[t]{2}{*}{ C3 } & $N$-dealkylation & 7.23 & $\mathrm{C}_{15} \mathrm{H}_{21} \mathrm{FN}_{2} \mathrm{O}$ & 265.1710 & -0.38 & $4.9 \mathrm{E}+04$ & $5.0 \mathrm{E}+06$ & $8.1 \mathrm{E}+06$ & $9.2 \mathrm{E}+06$ & $1.5 \mathrm{E}+07$ & $3.8 \mathrm{E}+06$ & $1.2 \mathrm{E}+07$ & $3.0 \mathrm{E}+06$ & 84.0806 \\
\hline & & & & & & & & & & $1.5 \mathrm{E}+07$ & $3.8 \mathrm{E}+06$ & $1.2 \mathrm{E}+07$ & $3.3 \mathrm{E}+06$ & \\
\hline \multirow[t]{2}{*}{ C4 } & $\begin{array}{l}\text { Dihydrodiol } \\
\text { formation (at } \\
\text { ethylphenyl) }\end{array}$ & 7.46 & $\mathrm{C}_{23} \mathrm{H}_{31} \mathrm{FN}_{2} \mathrm{O}_{3}$ & 403.2387 & -0.51 & ND & $4.6 \mathrm{E}+04$ & $8.0 \mathrm{E}+04$ & $9.8 \mathrm{E}+04$ & $2.3 \mathrm{E}+05$ & $2.9 E+04$ & $6.9 E+05$ & $1.6 \mathrm{E}+05$ & $\begin{array}{l}121.0639, \\
150.0701, \\
164.0874, \\
207.1286, \\
234.1250\end{array}$ \\
\hline & & & & & & & & & & $2.3 \mathrm{E}+05$ & $3.0 \mathrm{E}+04$ & $7.6 \mathrm{E}+05$ & $1.9 \mathrm{E}+05$ & \\
\hline \multirow[t]{2}{*}{ C5 } & $\begin{array}{l}\text { Hydroxylation + } \\
\text { glucuronidation }\end{array}$ & 7.51 & $\mathrm{C}_{29} \mathrm{H}_{37} \mathrm{FN}_{2} \mathrm{O}_{8}$ & 561.2607 & -0.11 & ND & ND & ND & ND & ND & ND & ND & ND & $\begin{array}{l}103.0512 \\
121.0644 \\
204.1406 \\
\end{array}$ \\
\hline & & & & & & & & & & $4.2 E+04$ & $1.2 \mathrm{E}+04$ & $1.7 \mathrm{E}+05$ & $1.5 \mathrm{E}+04$ & \\
\hline \multirow[t]{2}{*}{ C6 } & $\begin{array}{l}\text { Di-hydroxylation \& } \\
\text { methylation \& } \\
\text { glucuronidation }\end{array}$ & 7.6 & $\mathrm{C}_{3} \mathrm{OH}_{39} \mathrm{FN}_{2} \mathrm{O}_{9}$ & 591.2714 & -0.28 & ND & ND & ND & ND & ND & ND & ND & ND & $\begin{array}{l}84.0808, \\
119.0486, \\
151.0747, \\
234.1486, \\
415.2304\end{array}$ \\
\hline & & & & & & & & & & $2.9 E+04$ & $2.8 \mathrm{E}+04$ & $2.0 \mathrm{E}+05$ & $1.2 \mathrm{E}+04$ & \\
\hline
\end{tabular}

33 | P a g e 


\begin{tabular}{|c|c|c|c|c|c|c|c|c|c|c|c|c|c|c|}
\hline C7 & Hydroxylation & 7.97 & $\mathrm{C}_{23} \mathrm{H}_{29} \mathrm{FN}_{2} \mathrm{O}_{2}$ & 385.2283 & -1.02 & ND & ND & ND & ND & $7.1 \mathrm{E}+04$ & ND & $1.0 \mathrm{E}+05$ & $1.9 \mathrm{E}+04$ & $\begin{array}{l}105.0693 \\
188.1407\end{array}$ \\
\hline & & & & & & & & & & $5.7 E+04$ & ND & $5.9 \mathrm{E}+04$ & ND & \\
\hline \multirow[t]{3}{*}{ C8 } & Hydroxylation & 8.28 & $\mathrm{C}_{23} \mathrm{H}_{29} \mathrm{FN}_{2} \mathrm{O}_{2}$ & 385.2294 & 1.67 & ND & $7.9 E+04$ & $1.5 \mathrm{E}+05$ & $2.0 \mathrm{E}+05$ & ND & ND & ND & ND & 105.0698, \\
\hline & & & & & & & & & & & & & & 188.1434 \\
\hline & & & & & & & & & & ND & ND & ND & ND & \\
\hline \multirow[t]{6}{*}{ C9 } & Dihydroxylation & 8.44 & $\mathrm{C}_{23} \mathrm{H}_{29} \mathrm{FN}_{2} \mathrm{O}_{3}$ & 401.2231 & -0.66 & ND & ND & ND & ND & $9.1 \mathrm{E}+04$ & $3.7 E+04$ & $1.5 \mathrm{E}+06$ & $5.0 \mathrm{E}+04$ & 84.0805 \\
\hline & & & & & & & & & & & & & & 91.0534 \\
\hline & & & & & & & & & & & & & & 119.0484, \\
\hline & & & & & & & & & & & & & & 137.0590, \\
\hline & & & & & & & & & & & & & & 220.1323 \\
\hline & & & & & & & & & & ND & ND & $6.9 \mathrm{E}+04$ & $1.9 \mathrm{E}+04$ & \\
\hline \multirow[t]{4}{*}{ C10 } & Hydroxylation & 8.95 & $\mathrm{C}_{23} \mathrm{H}_{29} \mathrm{FN}_{2} \mathrm{O}_{2}$ & 385.2284 & -0.65 & ND & $1.7 \mathrm{E}+05$ & $2.9 \mathrm{E}+05$ & $4.0 \mathrm{E}+05$ & $1.0 \mathrm{E}+06$ & $1.9 \mathrm{E}+05$ & $3.1 \mathrm{E}+06$ & $1.7 \mathrm{E}+05$ & 103.0543, \\
\hline & & & & & & & & & & & & & & 121.0645, \\
\hline & & & & & & & & & & & & & & 204.1368 \\
\hline & & & & & & & & & & $3.7 \mathrm{E}+05$ & $4.2 \mathrm{E}+04$ & $6.3 \mathrm{E}+05$ & $6.2 \mathrm{E}+04$ & \\
\hline \multirow{3}{*}{ C11 } & & & & & & & & & & & & & & 121.0642, \\
\hline & & & & & & & & & & & & & & 204.1368 \\
\hline & & & & & & & & & & ND & ND & ND & ND & \\
\hline \multirow[t]{6}{*}{ C12 } & Di-hydroxylation \& & 9.17 & $\mathrm{C}_{24} \mathrm{H}_{31} \mathrm{FN}_{2} \mathrm{O}_{3}$ & 415.2395 & 0.62 & ND & $1.8 \mathrm{E}+04$ & $3.1 \mathrm{E}+04$ & $5.3 E+04$ & $5.6 \mathrm{E}+05$ & $4.6 \mathrm{E}+05$ & $3.5 \mathrm{E}+06$ & $1.6 \mathrm{E}+05$ & 84.0810 \\
\hline & methylation & & & & & & & & & & & & & 91.0537, \\
\hline & & & & & & & & & & & & & & 119.0493, \\
\hline & & & & & & & & & & & & & & 151.0751, \\
\hline & & & & & & & & & & & & & & 234.1474 \\
\hline & & & & & & & & & & $8.3 E+04$ & $3.3 E+04$ & $3.6 \mathrm{E}+05$ & $3.7 E+04$ & \\
\hline \multirow[t]{6}{*}{ C13 } & Di-hydroxylation \& & 9.37 & $\mathrm{C}_{24} \mathrm{H}_{31} \mathrm{FN}_{2} \mathrm{O}_{4}$ & 415.2393 & 0.34 & ND & ND & ND & ND & ND & ND & $7.3 E+04$ & $1.3 \mathrm{E}+04$ & 84.0801 \\
\hline & methylation & & & & & & & & & & & & & 91.0523 \\
\hline & & & & & & & & & & & & & & 119.0473, \\
\hline & & & & & & & & & & & & & & 151.0744, \\
\hline & & & & & & & & & & & & & & 234.1421 \\
\hline & & & & & & & & & & ND & ND & ND & ND & \\
\hline \multirow{3}{*}{ C14 } & & & & & & & & & & & & & & 132.0808, \\
\hline & & & & & & & & & & & & & & 164.0870, \\
\hline & & & & & & & & & & & & & & 188.1431 \\
\hline
\end{tabular}

34| Page 


\begin{tabular}{|c|c|c|c|c|c|c|c|c|c|c|c|c|c|c|}
\hline & & & & & & & & & & ND & ND & ND & ND & \\
\hline \multirow[t]{2}{*}{ C15 } & Hydroxylation & 9.56 & $\mathrm{C}_{23} \mathrm{H}_{29} \mathrm{FN}_{2} \mathrm{O}_{2}$ & 385.2280 & -1.04 & ND & $1.7 \mathrm{E}+06$ & $2.7 \mathrm{E}+06$ & $3.8 \mathrm{E}+06$ & $4.0 \mathrm{E}+06$ & $1.8 \mathrm{E}+05$ & $1.2 \mathrm{E}+06$ & $1.6 \mathrm{E}+05$ & $\begin{array}{l}91.0547, \\
105.0701, \\
132.0810, \\
150.0709, \\
174.1281, \\
186.1275, \\
204.1365\end{array}$ \\
\hline & & & & & & & & & & $1.9 \mathrm{E}+06$ & $1.2 \mathrm{E}+05$ & $7.9 \mathrm{E}+05$ & $7.7 \mathrm{E}+04$ & \\
\hline \multirow[t]{2}{*}{ C16 } & Carbonylation & 10.16 & $\mathrm{C}_{23} \mathrm{H}_{27} \mathrm{FN}_{2} \mathrm{O}_{2}$ & 383.2125 & -1.12 & ND & $2.1 \mathrm{E}+04$ & $2.5 \mathrm{E}+04$ & $3.3 \mathrm{E}+04$ & ND & ND & ND & ND & $\begin{array}{l}91.0532, \\
148.0752, \\
174.0921, \\
202.1201\end{array}$ \\
\hline & & & & & & & & & & ND & ND & ND & ND & \\
\hline $\mathbf{P}$ & $\begin{array}{l}\text { 4-fluoro- } \\
\text { isobutyrylfentanyl }\end{array}$ & 10.38 & $\mathrm{C}_{23} \mathrm{H}_{29} \mathrm{FN}_{2} \mathrm{O}$ & 369.2343 & 1.10 & $2.6 \mathrm{E}+07$ & $2.4 \mathrm{E}+07$ & $2.2 \mathrm{E}+07$ & $2.2 \mathrm{E}+07$ & $1.2 \mathrm{E}+07$ & $3.6 \mathrm{E}+05$ & $6.8 \mathrm{E}+06$ & $1.9 \mathrm{E}+06$ & $\begin{array}{l}105.0698, \\
188.1434\end{array}$ \\
\hline C17 & Hydroxylation & 11.48 & $\mathrm{C}_{23} \mathrm{H}_{29} \mathrm{FN}_{2} \mathrm{O}_{2}$ & 385.2296 & 2.43 & ND & $2.0 \mathrm{E}+05$ & $3.1 \mathrm{E}+05$ & $3.1 \mathrm{E}+05$ & ND & ND & ND & ND & $\begin{array}{l}105.0700, \\
164.0869\end{array}$ \\
\hline
\end{tabular}

HYD: hydrolyzed; NON-HYD: non-hydrolyzed; ND: Not detected; RT: retention time, P: parent compound 
Table 4: Furanylfentanyl metabolites with proposed biotransformation, retention time, elemental composition, accurate mass of protonated molecule, mass error of proposed metabolite, MS peak areas in hepatocyte samples ( $0 \mathrm{~h}, 1 \mathrm{~h}, 3 \mathrm{~h}$ and $5 \mathrm{~h}$ ) and in five urine samples (hydrolyzed and non-hydrolyzed), and diagnostic product ions (masses and mass errors generally taken from sample \#5, except for D6, D9, D11, D12 and D13 (hepatocytes).

Biotransformation

$\begin{array}{cccc}\text { RT } & \text { Elemental } & m / z & \text { mass } \\ (\min ) & \text { composition } & & \text { er }\end{array}$

\begin{tabular}{llccc} 
& \multicolumn{4}{c}{ Peak areas in hepatocytes } \\
mass & Oh & $1 \mathrm{~h}$ & $3 \mathrm{~h}$ & $5 \mathrm{~h}$ \\
error & & & & \\
ppm) & & & & \\
\end{tabular}

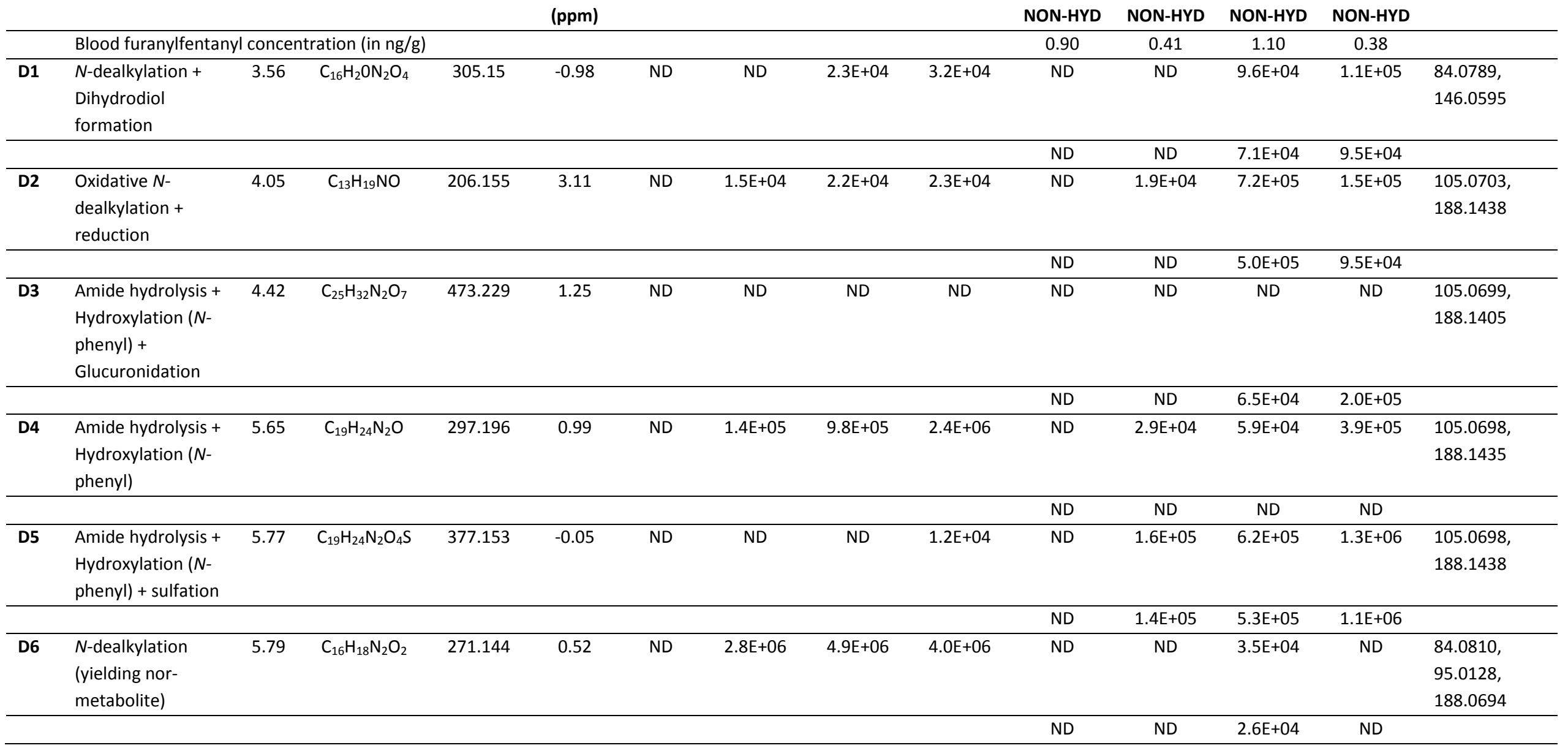

36| Page 


\begin{tabular}{|c|c|c|c|c|c|c|c|c|c|c|c|c|c|c|}
\hline D7 & $\begin{array}{l}\text { Dihydrodiol } \\
\text { formation + } \\
\text { Hydroxylation } \\
\text { (ethyl) }\end{array}$ & 5.82 & $\mathrm{C}_{24} \mathrm{H}_{28} \mathrm{~N}_{2} \mathrm{O}_{5}$ & 425.207 & 0.82 & ND & $1.9 \mathrm{E}+04$ & $3.8 \mathrm{E}+04$ & $2.7 \mathrm{E}+04$ & ND & $2.3 \mathrm{E}+05$ & $1.6 \mathrm{E}+05$ & $4.6 \mathrm{E}+05$ & $\begin{array}{l}103.0562, \\
121.0649\end{array}$ \\
\hline & & & & & & & & & & ND & $1.4 \mathrm{E}+05$ & $7.9 E+04$ & $2.8 \mathrm{E}+05$ & \\
\hline \multirow[t]{2}{*}{ D8 } & $\begin{array}{l}\text { Amide hydrolysis + } \\
\text { Hydroxylation } \\
\text { (ethyl) }\end{array}$ & 7.19 & $\mathrm{C}_{19} \mathrm{H}_{24} \mathrm{~N}_{2} \mathrm{O}$ & 297.196 & -0.03 & ND & $6.5 \mathrm{E}+04$ & $2.0 \mathrm{E}+05$ & $2.6 \mathrm{E}+05$ & ND & $4.1 \mathrm{E}+04$ & $1.2 \mathrm{E}+05$ & $2.6 \mathrm{E}+05$ & $\begin{array}{l}103.0529, \\
121.0646\end{array}$ \\
\hline & & & & & & & & & & ND & ND & $7.4 \mathrm{E}+04$ & $1.6 \mathrm{E}+05$ & \\
\hline \multirow[t]{2}{*}{ D9 } & $\begin{array}{l}\text { Furan ring opening } \\
+ \text { Carboxylation }\end{array}$ & 7.38 & $\mathrm{C}_{24} \mathrm{H}_{28} \mathrm{~N}_{2} \mathrm{O}_{3}$ & 393.2175 & 0.25 & ND & ND & ND & $3.0 \mathrm{E}+04$ & ND & ND & ND & ND & $\begin{array}{l}105.0693, \\
188.1448\end{array}$ \\
\hline & & & & & & & & & & ND & ND & ND & ND & \\
\hline \multirow[t]{2}{*}{ D10 } & $\begin{array}{l}\text { Dihydrodiol } \\
\text { formation }\end{array}$ & 7.5 & $\mathrm{C}_{24} \mathrm{H}_{28} \mathrm{~N}_{2} \mathrm{O}_{4}$ & 409.212 & -0.34 & ND & $1.8 \mathrm{E}+06$ & $3.5 \mathrm{E}+06$ & $2.9 \mathrm{E}+06$ & ND & $4.8 \mathrm{E}+05$ & $2.3 \mathrm{E}+05$ & $1.3 \mathrm{E}+06$ & $\begin{array}{l}105.0698, \\
188.1440\end{array}$ \\
\hline & & & & & & & & & & ND & $3.0 \mathrm{E}+05$ & $1.8 \mathrm{E}+05$ & $9.5 \mathrm{E}+05$ & \\
\hline \multirow[t]{2}{*}{ D11 } & $\begin{array}{l}\text { Hydroxylation } \\
\text { (ethyl) }\end{array}$ & 7.86 & $\mathrm{C}_{24} \mathrm{H}_{26} \mathrm{~N}_{2} \mathrm{O}_{3}$ & 391.2018 & 0.99 & ND & $4.6 \mathrm{E}+04$ & $3.7 \mathrm{E}+04$ & $1.4 \mathrm{E}+04$ & ND & ND & ND & ND & 121.0649 \\
\hline & & & & & & & & & & ND & ND & ND & ND & \\
\hline \multirow[t]{2}{*}{ D12 } & $\begin{array}{l}\text { Amide hydrolysis + } \\
\text { Hydroxylation } \\
\text { (piperidine) }\end{array}$ & 7.99 & $\mathrm{C}_{19} \mathrm{H}_{24} \mathrm{~N}_{2} \mathrm{O}$ & 297.1963 & 0.96 & ND & $3.3 \mathrm{E}+05$ & $1.1 \mathrm{E}+06$ & $1.3 \mathrm{E}+06$ & ND & ND & ND & ND & $\begin{array}{l}91.0539, \\
105.0690, \\
132.0818\end{array}$ \\
\hline & & & & & & & & & & ND & ND & ND & ND & \\
\hline \multirow[t]{2}{*}{ D13 } & $\begin{array}{l}\text { Hydroxylation } \\
\text { (probably at } \\
\text { piperidine) }\end{array}$ & 8.52 & $\mathrm{C}_{24} \mathrm{H}_{26} \mathrm{~N}_{2} \mathrm{O}_{3}$ & 391.2024 & 1.65 & ND & $4.1 \mathrm{E}+05$ & $4.3 \mathrm{E}+05$ & $1.8 \mathrm{E}+05$ & ND & ND & ND & ND & $\begin{array}{l}91.0538, \\
132.0792\end{array}$ \\
\hline & & & & & & & & & & ND & ND & $N D$ & ND & \\
\hline \multirow[t]{2}{*}{ D14 } & Amide hydrolysis & 9.05 & $\mathrm{C}_{19} \mathrm{H}_{24} \mathrm{~N}_{2}$ & 281.202 & 1.22 & $2.0 \mathrm{E}+04$ & $1.0 \mathrm{E}+07$ & $1.7 \mathrm{E}+07$ & $1.8 \mathrm{E}+07$ & $5.9 \mathrm{E}+04$ & $4.9 \mathrm{E}+05$ & $5.4 \mathrm{E}+05$ & $3.8 \mathrm{E}+06$ & $\begin{array}{l}105.0697, \\
188.1433 \\
\end{array}$ \\
\hline & & & & & & & & & & ND & $3.5 \mathrm{E}+05$ & $3.8 \mathrm{E}+05$ & $2.9 \mathrm{E}+06$ & \\
\hline \multirow[t]{2}{*}{$\mathbf{P}$} & Furanylfentanyl & 9.38 & $\mathrm{C}_{24} \mathrm{H}_{26} \mathrm{~N}_{2} \mathrm{O}_{2}$ & 375.207 & 0.62 & $2.5 \mathrm{E}+07$ & $2.1 \mathrm{E}+07$ & $1.6 \mathrm{E}+07$ & $1.0 \mathrm{E}+07$ & $1.6 \mathrm{E}+04$ & $3.8 \mathrm{E}+05$ & $6.7 \mathrm{E}+04$ & $2.2 \mathrm{E}+06$ & $\begin{array}{l}105.0699, \\
188.1433\end{array}$ \\
\hline & & & & & & & & & & $1.5 \mathrm{E}+04$ & $2.9 \mathrm{E}+05$ & $1.8 \mathrm{E}+05$ & $1.6 \mathrm{E}+06$ & \\
\hline
\end{tabular}

HYD: hydrolyzed; NON-HYD: non-hydrolyzed; ND: Not detected; RT: retention time, P: parent compound

* The corresponding blood sample of urine \#4 contained $1.2 \mathrm{ng} / \mathrm{g}$ fentanyl

\section{7 | P a g e}




\section{Figures}

Fig. 1
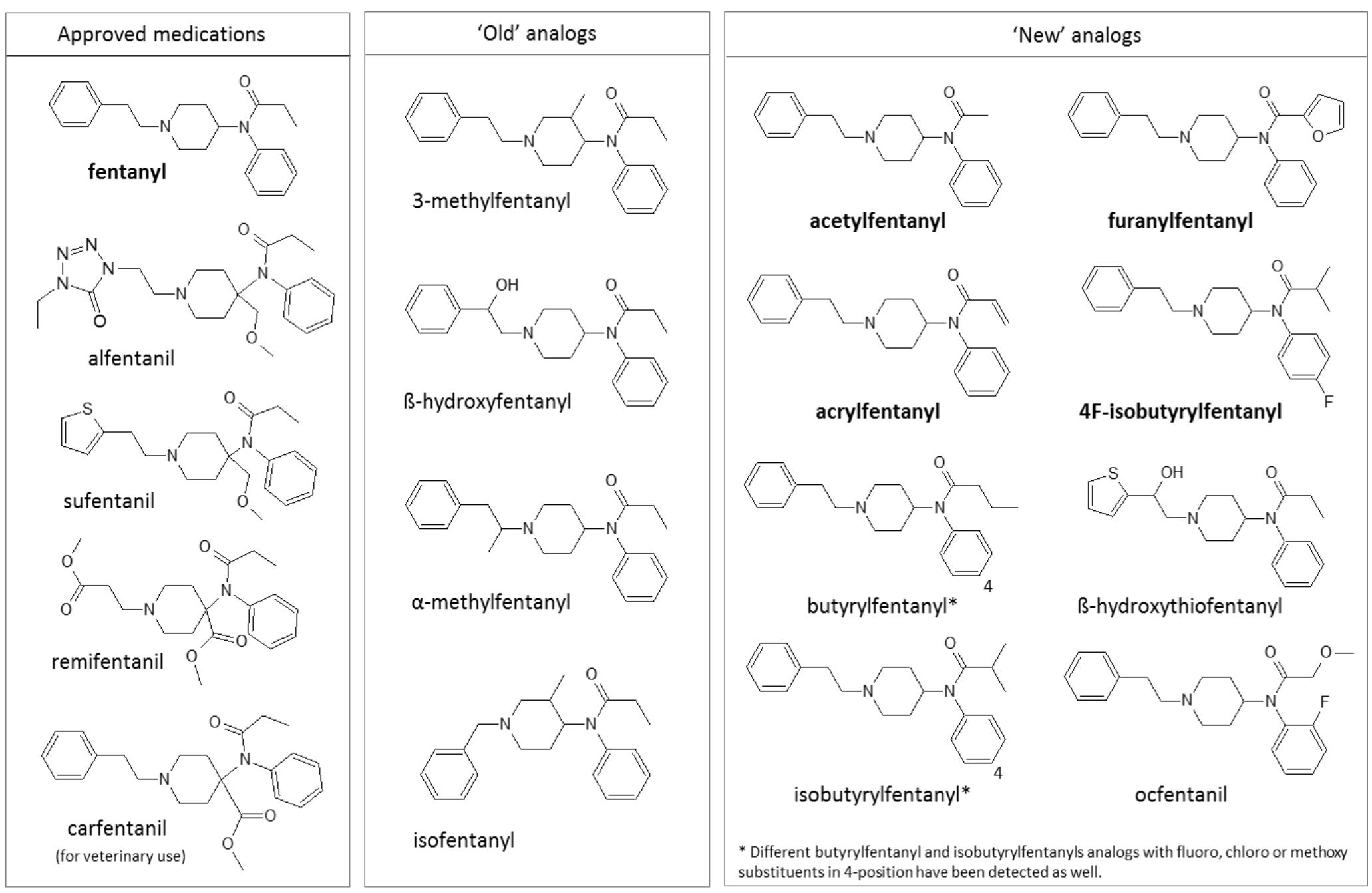

38 | P a g e 
Fig. 2

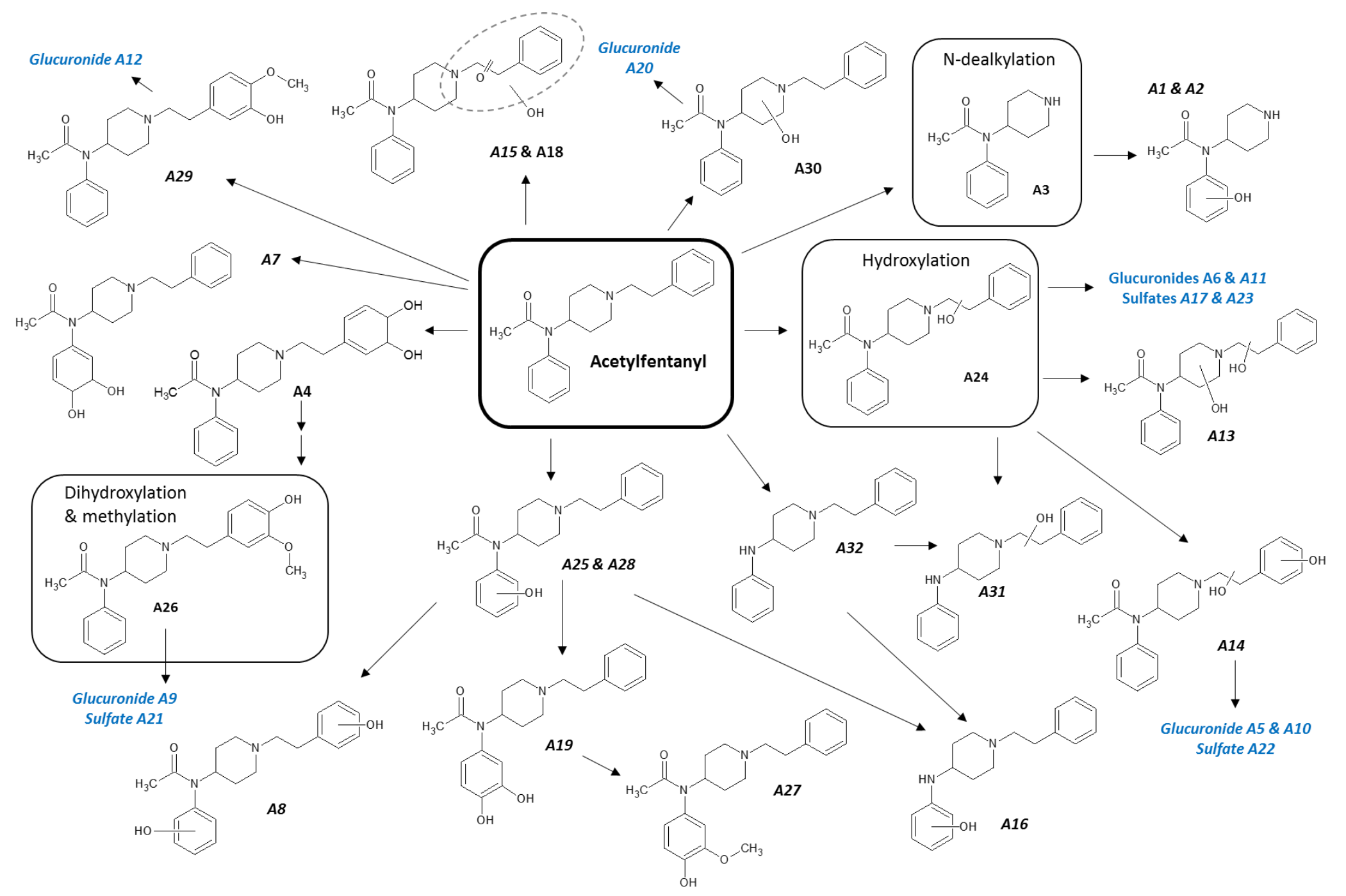


Fig. 3

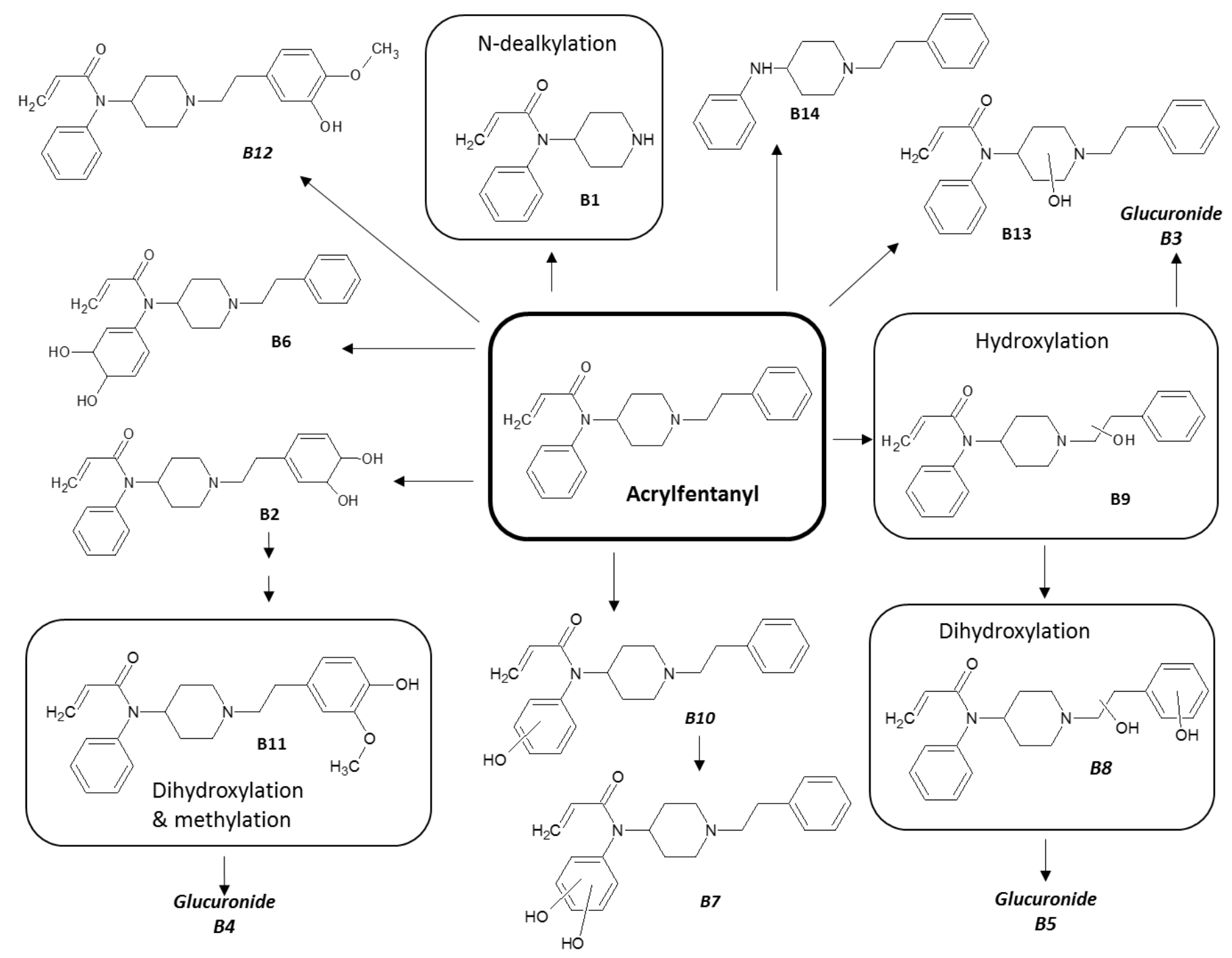


Fig. 4

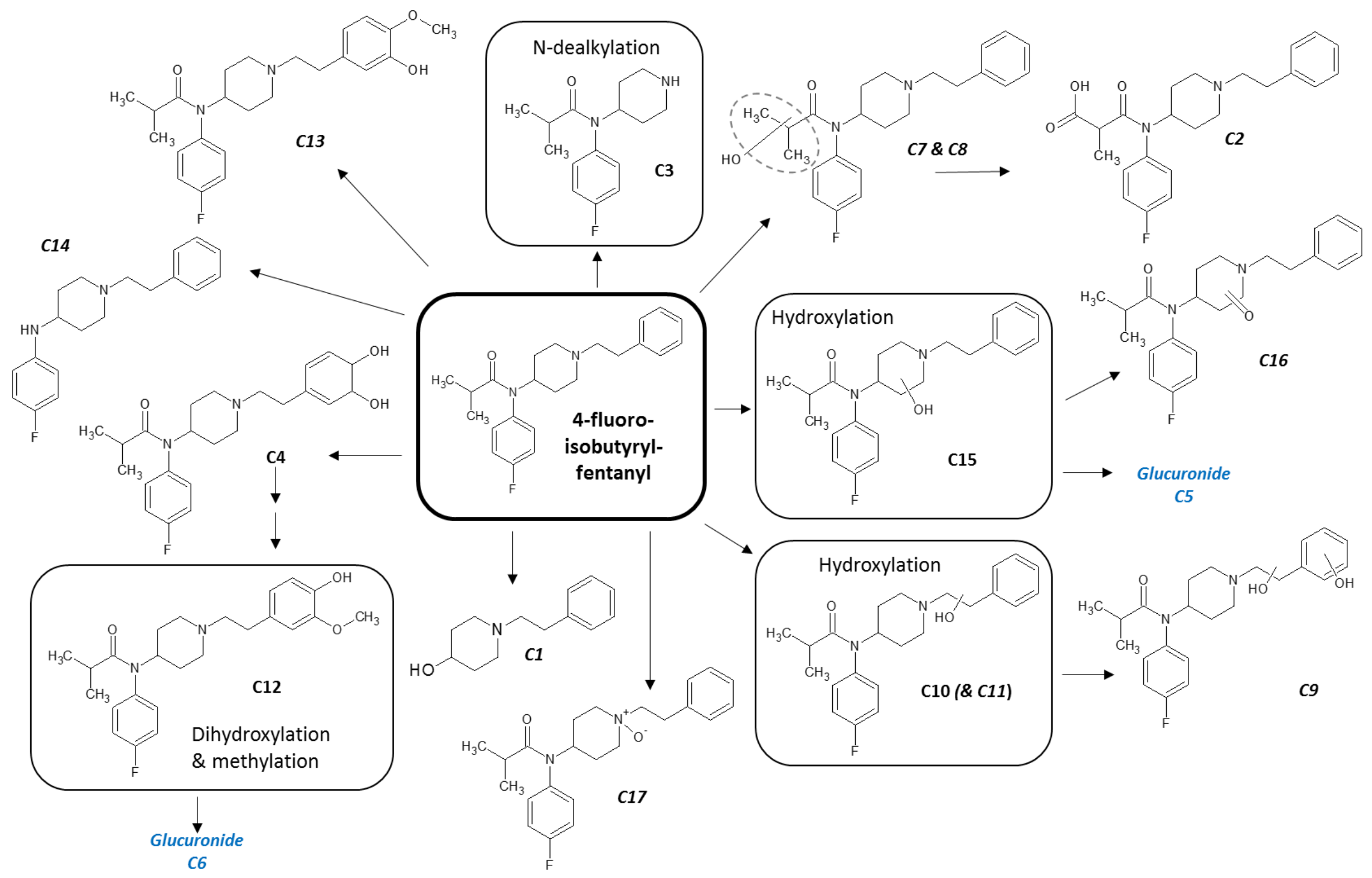


Fig. 5

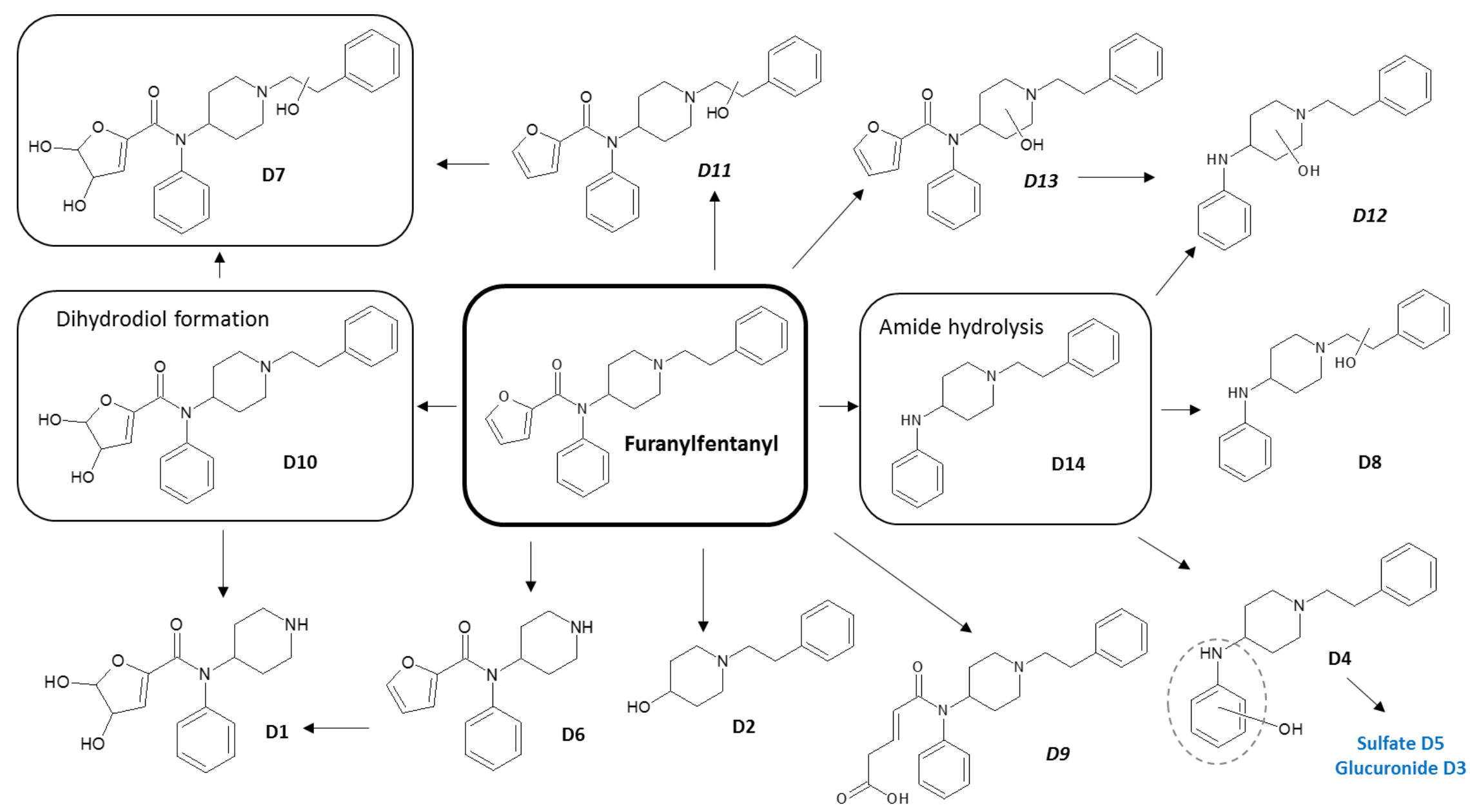




\section{Supplementary figures}

Supplementary Fig. 1: MSMS spectra and proposed fragmentation pattern of acetylfentanyl and its major metabolites in hydrolyzed human urine samples.
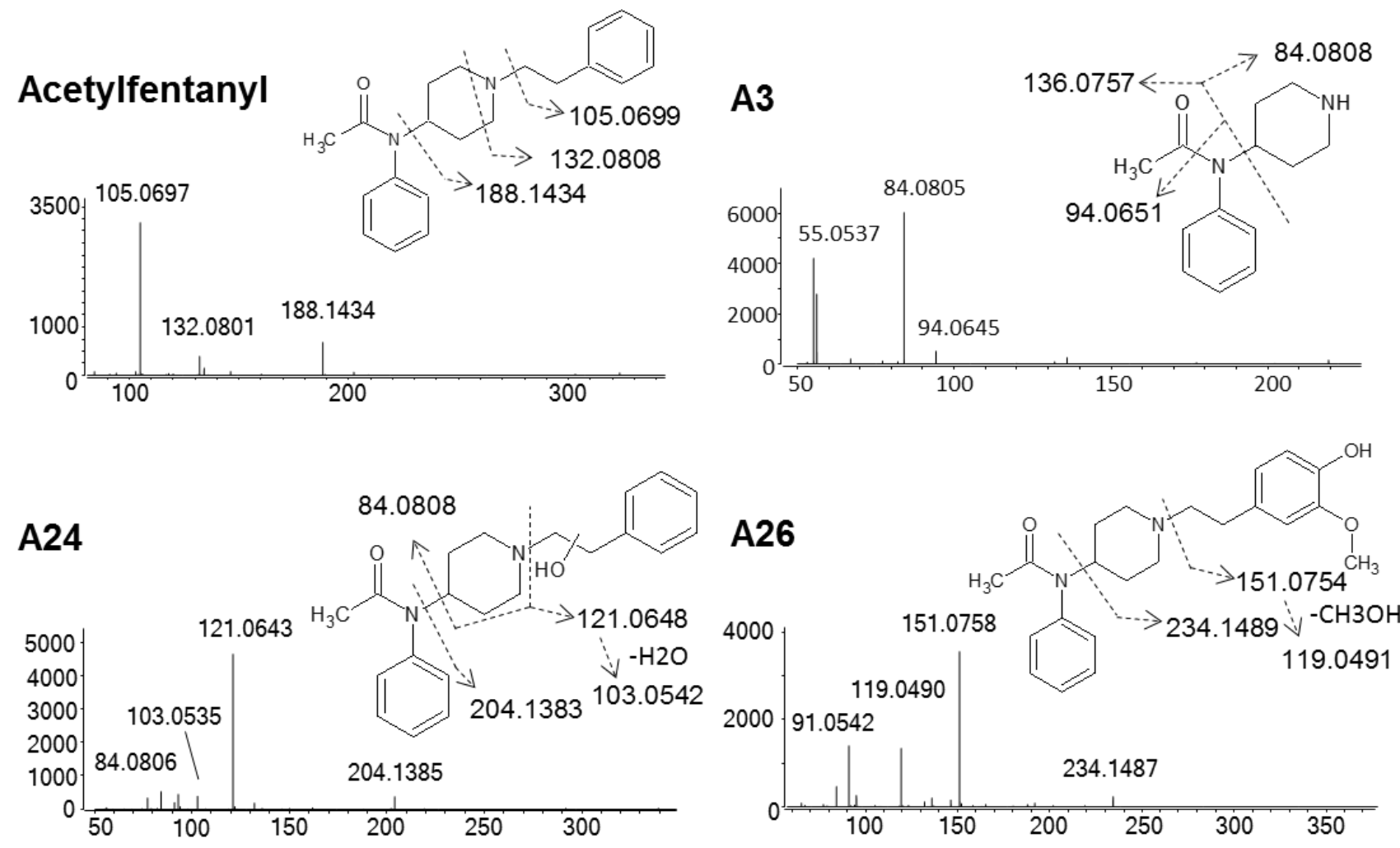
Supplementary Fig. 2: MSMS spectra and proposed fragmentation pattern of acrylfentanyl and its major metabolites in hydrolyzed human urine samples.
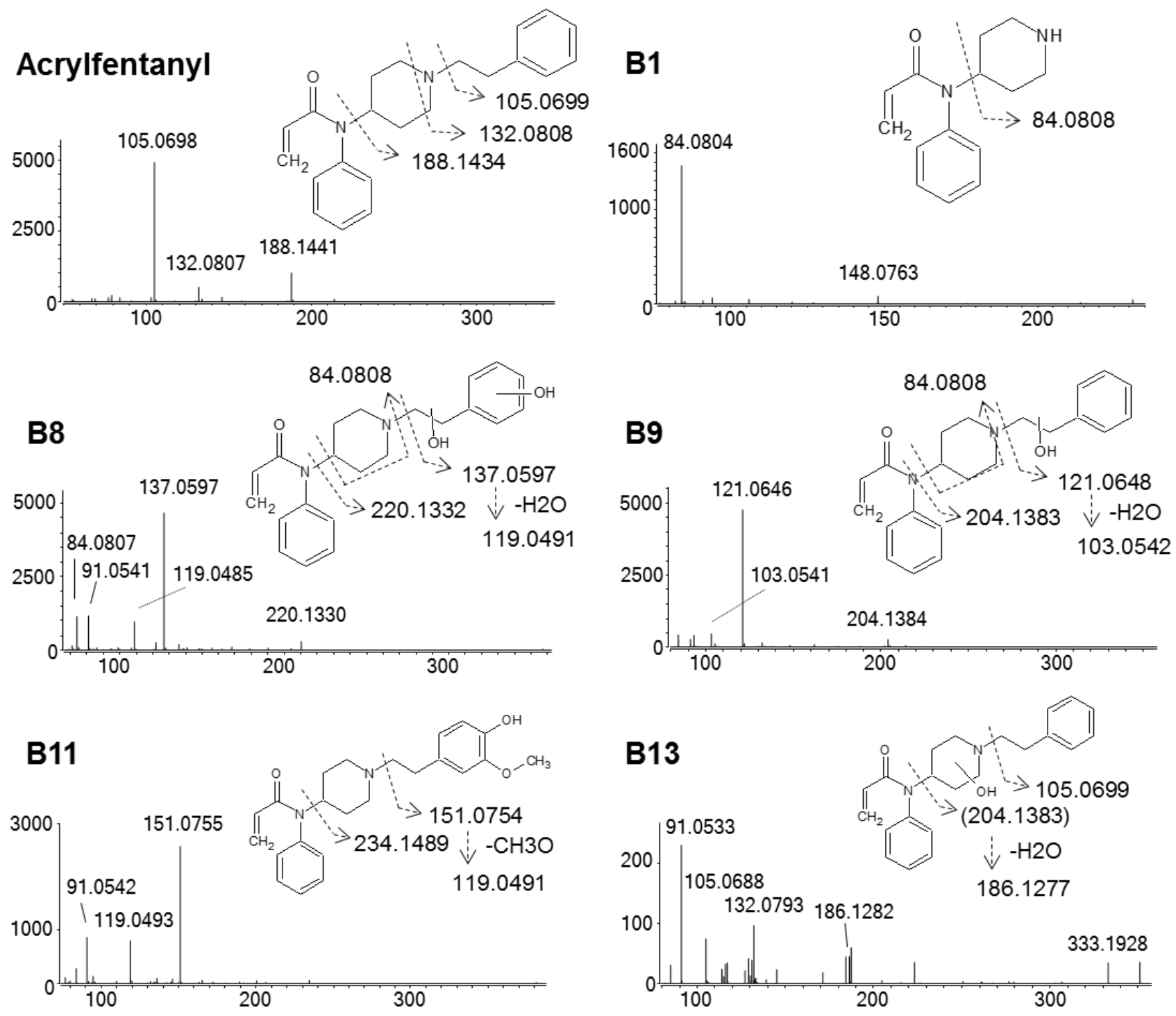
Supplementary Fig. 3: MSMS spectra and proposed fragmentation pattern of 4-

fluoroisobutyryllfentanyl and its major metabolites in hydrolyzed human urine samples.

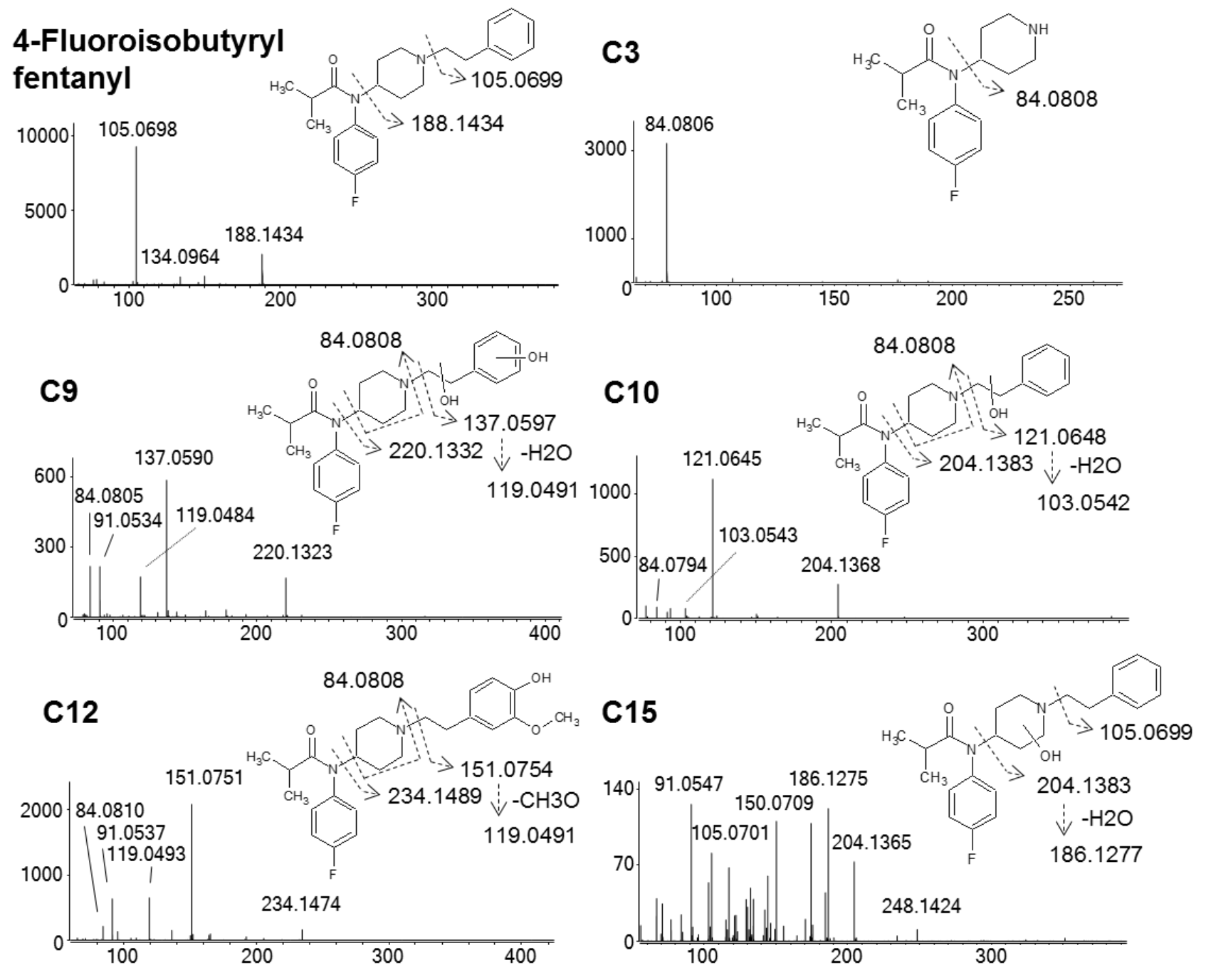


Supplementary Fig. 4: MSMS spectra and proposed fragmentation pattern of furanylfentanyl and its major metabolites in hydrolyzed human urine samples.
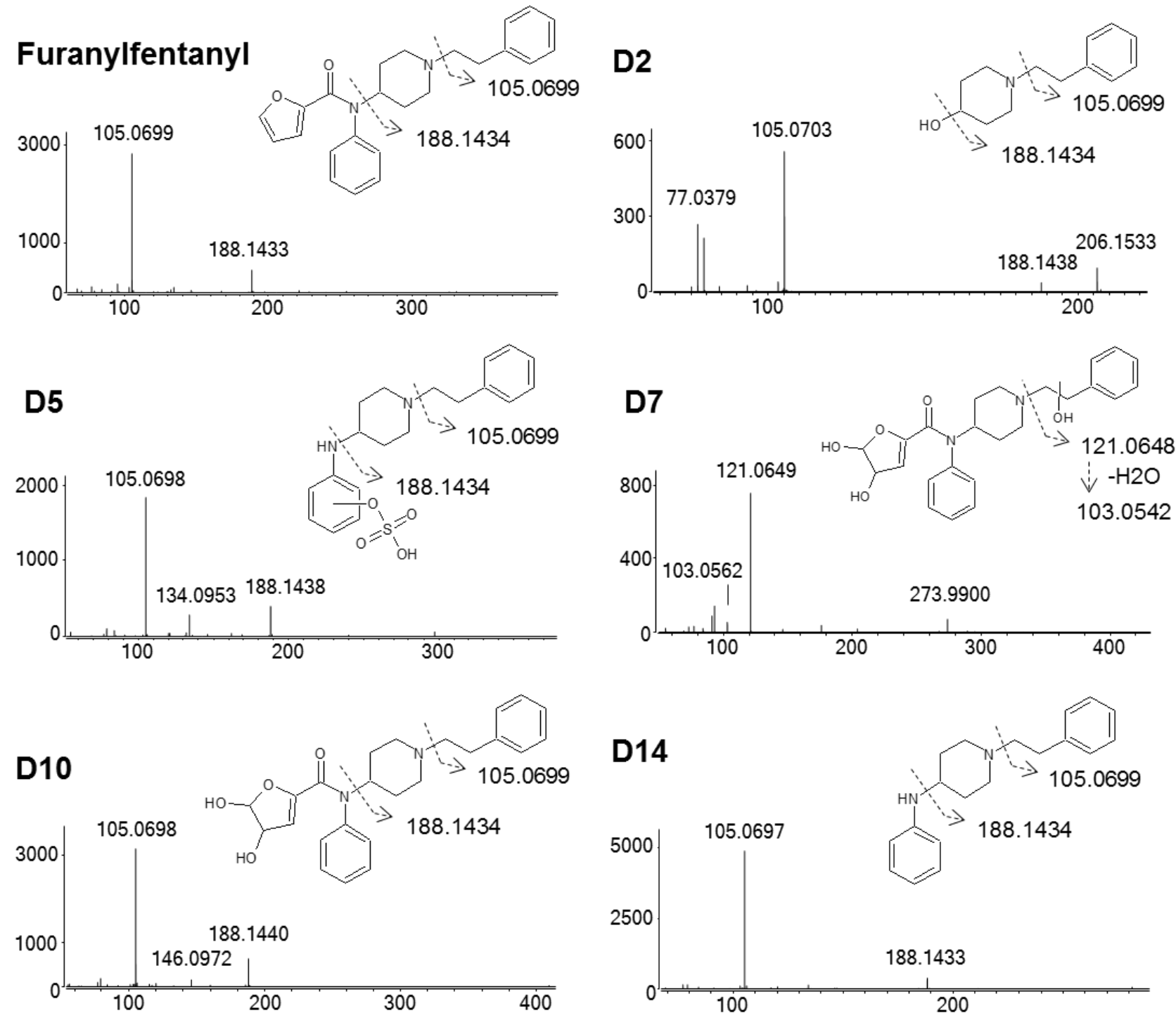